\title{
REPARANDO LAS HERIDAS: EL NACIMIENTO DE UNA DEVOCIÓN DE "CONTRARREFORMA"
}

\author{
Javier Burrieza Sánchez \\ Universidad de Valladolid
}

El siglo XVI fue el de la Reforma religiosa en toda Europa y desde las diferentes orillas, católica o protestante. La configuración de una Iglesia nacional para Inglaterra respondió a coordenadas políticas y religiosas sobradamente conocidas. Fruto de la persecución que se desencadenó en aquel reino contra los católicos, después de la promulgación del Acta de Supremacía por Enrique VIII y sobre todo por su hija Isabel I en 1559, se trasladaron a la Europa "romana" los centros dedicados a la formación teológica de los sacerdotes católicos. $\mathrm{Si}$ al principio los Colegios de Ingleses se vincularon al norte de Europa, a partir de 1588 la denominada Misión de Inglaterra encontró en la Monarquía hispánica un escenario perfecto para fundar estos seminarios.

Fue el jesuita inglés Robert Persons el que convirtió una incipiente comunidad de compatriotas huidos de su reino y estudiantes en la Universidad de Valladolid en un Seminario católico para Inglaterra. Una institución transformada en una baza política y religiosa de Felipe II hacia su antagonista, la reina Isabel I. Por eso no fue extraño que el monarca español apoyase con tanta decisión y visitase en 1592 este primer Colegio de Ingleses en España, único hoy de los que se fundaron con posterioridad.

Recibió este centro la advocación del primer mártir de los ingleses, San Albano, uno de aquellos legionarios del siglo III portadores de las nuevas ideas (las religiosas) del entonces Imperio Romano. Un santo sin mucho atractivo en España. Pero en 1600 apareció el segundo de los elementos. La flota inglesa había atacado Cádiz en 1596. Una pequeña imagen de una Virgen con el Niño, que recibía culto en su Catedral, se convirtió en el símbolo de una guerra que ya tenía proporciones religiosas. La imagen fue mutilada y maltratada por las tropas asaltantes que saquearon la ciudad andaluza. Los seminaristas ingleses que estudiaban en Valladolid, dirigidos por los jesuitas, reclamaron esta imagen 
para su Colegio, con el objeto de reparar espiritualmente las heridas de una Virgen destrozada por sus compatriotas anglicanos. Cuando llegó a esta ciudad en 1600 ella sí que se convirtió en el atractivo devocional del Seminario. Pronto fue una imagen "milagrera", pues aquellos prodigios eran necesarios e indispensables en una mentalidad religiosa que todo lo invadía. La construcción de esta devoción y la infraestructura que fue capaz de generar serán el objeto de interés de las siguientes páginas.

\section{CÁDIZ, 1596}

1596 marca un momento dramático en las relaciones entre Inglaterra y España. En Londres los partidarios del enfrentamiento armado directo con Felipe II triunfaron en el consejo, apoyando una propuesta del conde de Essex, el favorito de la reina Isabel y protector del antiguo secretario del monarca español, Antonio Pérez. El último día de junio de 1596, un enorme flota, a cuyo mando se encontraba lord Charles Howard, primer conde de Effingham y héroe que fue de la Armada, apareció en el horizonte de la ciudad de Cádiz: "la más hermosa que se ha visto", indicaba un testigo. Una belleza que se traducía en cuarenta buques de guerra, cien navíos más pequeños, diez mil soldados ingleses y cinco mil holandeses a las órdenes del segundo conde de Essex y de Luis de Nassau respectivamente. Al día siguiente las embarcaciones españolas que podían hacer frente se encontraban destruidas, desembarcando ingleses y holandeses en una ciudad que quedó a su merced durante dos semanas, con ausencia de sus posibles defensores. Y es que Cádiz era -como insiste Henry Kamen- el puerto español del comercio con las Indias americanas y el norte de Europa. Una ciudad pequeña eso sí, que se había convertido en el símbolo del poder marítimo de la Monarquía de Felipe II. Un poderío cuestionado ya, y ésta no era la primera vez, por la Inglaterra de la reina Isabel ${ }^{1}$.

A pesar de las palabras que dirigieron a las tropas sus superiores, grupos de soldados que desembarcaron por la ciudad se dedicaron a asaltar ferozmente sus distintas casas e iglesias, profanando una imagen a la que el pueblo profesaba una notable devoción, alumbrada en su Catedral. Era una Virgen, perteneciente a la escuela sevillana, que portaba en su regazo al Niño Jesús. Atraídos por la gran cantidad de gaditanos que se refugiaban en su Iglesia Mayor, comprobaron la devoción que profesaban hacia aquella imagen y comenzaron la profanación de la misma. Su rostro y su cuerpo recibieron sendos hachazos, que la privaron de algunas facciones de la cara y de las manos, arrancando la

1. H. KAMEN, Felipe de España, Madrid 1997, págs 324-325. Para las notas de pie de página, ACSA, Archivo Colegio de San Albano; ACV, Archivo Catedral de Valladolid; AMV, Archivo Municipal de Valladolid; AGS, Archivo General de Simancas. Este artículo se enmarca dentro de los trabajos del proyecto El catolicismo en España en la época moderna: el proceso de confesionalización (PB97-0755-CO3-03), del Ministerio de Ciencia y Tecnologia. 
imagen del Niño ${ }^{2}$. Las crónicas fueron detalladas con lo que había ocurrido y así las palabras servían de recreo inconsciente de un asalto ${ }^{3}$. Una devoción hacia una Virgen de la cual el jesuita Juan de Villafañe no se atreve a fijar noticias sobre su antigüedad y autoría ${ }^{4}$. Así dos elementos fueron comunes en todas las crónicas: el carácter público de la agresión y el dolor y lágrimas que fueron capaces de despertar la contemplación de la imagen agredida. Lágrimas siempre indispensables cuando se trataba de describir la virtud.

Henry Kamen, en su estudio sobre Felipe II, matiza un tanto los efectos de este ataque. Los ingleses quemaron iglesias, pero no las profanaron; asaltaron la ciudad, pero no violaron a sus mujeres. Y para hacer estas afirmaciones el conocido hispanista se basa en el informe del doctor Francisco de Quesada, intitulado Relación de lo que sucedió en la pérdida

2. "Hallándose invadida la Ciudad de Cádiz havrá unos ochenta años de los corsarios hereges de Inglaterra; destituida de todos humanos socorros en tan súbita aflicción sus vecinos, acudieron llenos de confianza por remedio como lo solía hacer en todas sus necessidades a una milagrosa imagen de la soberana Reyna de los Ángeles María Santíssima que residía en la Iglesia Cathedral de Cádiz. Irritados los hereges de tanta piedad cristiana e instigados por el demonio se atrevieron contra el trono de la misma Madre de Dios y quitándole el cetro real de la mano y la imperial corona de su caveza la arrojaron en el suelo y la lleuaron por las calles más públicas de la ciudad haciendo mil insolencias y desacatos en tan milagrosa imagen y llegando a la Plaza Mayor pusieron a SM en un alto y poniéndose en orden todo aquel escuadrón armado del Infierno, fueron todos por su turno a hazer un tiro este blanco de su indignación, con exquisitas invenciones de oprobios, afrentas e injurias, concluyendo su diabólico entretenimiento en probar los filos de sus espadas en la injuriada imagen de la Madre de Dios y cansados ya de herirla la dejaron postrada en el suelo, cubierta de polvo y lodo, cortados a cuchilladas los brazos, desgajando de ellos con violencia su Santísimo Hijo y tan desfigurado su divino rostro con las heridas que ni aun parecía sombra de lo que era", (ACSA, Serie II, Miscelánea, lib. 12, "Algunas apuntaciones de motivos que ay para favorecer este Colegio o Seminario Inglés de San Albano sito en esta Ciudad de Valladolid").

3. "Haziendo risa y mofa de lo que avían de sacar admiración, respeto y arrepentimiento de sus errores, acometieron con rabiosa furia a la Santa Imagen, arrancándola del trono, que ocupaba como Reyna, entre los baldones injuriosos que de palabra la dezían; la traxeron á la plaza más pública, para executar el sacrilegio, que ideaba su barbaridad, mas á la vista del Cielo y de la tierra. Puesta ya allí la preciosa imagen de la Reyna de los Ángeles; lo primero, que hizieron fue adorarla fingidamente con escarnio y vilipendio, á la manera, que los Soldados lo executaron con Jesu-Christo; y alterada más con esta fingida adoración, su ira y cólera, sacaron luego las espadas y probaron sus filos en tan sagrado simulacro, dando á la imagen muchas cuchilladas, con que la dividieron, y separaron los brazos hasta los codos, afeando también la hermosura de su rostro con siete heridas que la hizieron, y no perdonando tampoco su loco y sacrílego, atrevimiento al bello Niño que tenía en sus sagrados brazos la Madre; le hirieron también y ultrajaron separándole y arrancándole de ellos como oy lo ven, y Iloran los devotos, que con atención contemplan el rostro de esta gran Reyna que, como otra Raquel, lamenta y siente la falta y ausencia de su hijo", (J. VILLAFAÑE, Compendio Histórico en que se da noticia de las milagrosas y devotas imágenes de la Reyna de Cielos y Tierra, María Santíssima que se veneran en los más célebres santuarios de Hespaña. Refiriérense sus principios y progressos, con los principales milagros, que ha obrado Dios NS, por su intercesión y sucessos más notables de sus prodigiosos aparecimientos, Salamanca, Eugenio García de Honorato, 1726,pág. 579).

4. J. VILLAFAÑE, Compendio Histórico de los más célebres santuarios de nuestra Señora en España..., ob. cit., Salamanca, 1726, pág. 578. 
de Cádiz, año de $1596^{5}$. Un testimonio complementado por otros, cuando un oficial español señalaba que hasta en el ataque, los ingleses habían sido muy disciplinados. Eso sí, algunos holandeses -el cura que lo testimoniaba decía "flamencos"- gritaban "Colgad al papa".

El ataque inglés a Cádiz fue -como señala Henry Kamen- el hundimiento de un sentimiento de honor y reputación de España, "la verguença de nuestra nación", como apuntó un capitular de la Catedral de Burgos. En la Corte de Madrid se había celebrado un mes antes con júbilo la muerte del corsario inglés protegido por la reina Isabel, Francis Drake. Sin embargo este asalto demostraba que las costas españolas seguían encontrándose impunes, vulnerables, sin que pudiese existir razón alguna para el entusiasmo. Felipe II, personalmente, reaccionó con furia ante este acontecimiento. Era necesario conseguir la paz, pero con el suficiente honor y cierta actitud ofensiva. Así lo decía, Martín de Padilla, conde de Santa Gadea y Adelantado de Castilla, uno de los comandantes más importantes de la flota española. Padilla era partidario de reunir efectivos y de atacar definitivamente a Inglaterra. Con este asalto se conseguiría la paz, pero la victoria permitiría imponer condiciones españolas. Quizás era la última oportunidad para superar el fantasma de 1588.

Lo primero que se encargó a Martín de Padilla fue el preparar una fuerza naval en el Atlántico que detuviese la amenaza inglesa contra las costas españolas. Felipe II contaba con un memorial, que había sido redactado por el jesuita Robert Persons, el fundador del Colegio de Ingleses de Valladolid, donde retrataba la situación en Irlanda y proponía una invasión ${ }^{6}$. Así se lo comunicó el monarca al Adelantado de Castilla. Sin embargo el objetivo real era Francia. De hecho la flota de casi cien grandes navíos que partió de Lisboa y La Coruña, comandada por Padilla, divulgaba su dirección hacia Irlanda, cuando en realidad había tomado rumbo hacia Bretaña, con el objetivo de capturar Brest. De nuevo los "elementos" se ensañaron contra los barcos en las aguas del Canal de la Mancha, perdiéndose el galeón más grande que llevaba el dinero. Cuando en noviembre informaba Padilla al monarca, habían regresado la mitad de los navíos que habían zarpado. Lo más positivo es que en ese año1597 Martín de Padilla contaba con una fuerza para repeler futuros ataques como los de Cádiz. Un nuevo intento se produjo en ese año, pero un nueva tormenta aconsejó a Padilla ser más prudente y regresar antes. Como indica Kamen, no había que culpar a nadie, "porque los vientos eran obra de Dios". Lo malo era comprobar que en el fondo ésto era una lucha entre católicos y anglicanos. Padilla, a finales de 1597 transportaba hombres a Flandes. Si se quería atacar Inglaterra se necesitaría, y así se lo exponía a Felipe II, una detenida preparación .

5. AGS, Estado, leg 177. "Informe del doctor Francisco de Quesada. Relación de lo que sucedió en la pérdida de Cádiz, año de 1596".

6. AGS, Estado, leg 176. Carta del Rey Felipe II y memorial de Persons.

7. H. KAMEN, Felipe de España.., ob cit, págs 324-327. 
Los seminaristas ingleses de Valladolid tuvieron conocimiento del destrozo que sus compatriotas habían realizado de esta Virgen gaditana y solicitaron la posibilidad de reparar los daños espirituales que se habían infringido contra la imagen. Ésta había sido trasladada a Madrid, precisamente por la condesa de Santa Gadea, Luisa de Padilla, la esposa del Adelantado y hermana del padre Antonio de Padilla, uno de los jesuitas más notables de la provincia de Castilla. La condesa la había situado en su capilla ${ }^{8}$. Precisamente las clases que su hermano impartía a los seminaristas ingleses en el Colegio vallisoletano de San Ambrosio, animaron a Luisa de Padilla a confiar el culto de esta Virgen a los colegiales de San Albano, tal y como éstos lo habían solicitado ${ }^{9}$. Así también lo habían apoyado los superiores de la provincia de Castilla. Eso sí, las negociaciones fueron prolongadas.

Eran los días en los cuales se rumoreaba sobre un regreso de la Corte a Valladolid. Así lo recordaba Cabrera de Córdoba en sus Relaciones: "por haber tantos años que los reyes no visitan aquella tierra" ${ }^{\prime 10}$. De hecho la Corte salió del Real Sitio de El Pardo a principios de junio, deteniéndose en Segovia, Salamanca, Medina del Campo y breve estancia en Tordesillas, en el palacio que allí poseían. Según escribe Juan de Villafañe, en esta localidad Felipe III y Margarita de Austria recibieron a un jesuita inglés que se hallaba en San Albano, con el objeto de participar a los monarcas de los deseos de los seminaristas de contar con esta Virgen mutilada. Los reyes escribieron cartas recomendatorias al obispo y corregidor de Valladolid, autorizando y promoviendo más directa o indirectamente esta imagen. Las palabras del rey Felipe encomiaron a los Adelantados de Castilla a un traspaso de la misma.

8. "Dispusieron traher de secreto, desde Cádiz, á Madrid, la Santa Imagen, y la introduxeron en su misma casa, y Oratorio, esperando más bendiciones del Cielo, por tener consigo esta Arca del Testamento, que las que alcanzó Obededón, por aver estado en la suya la otra, espacio de tres meses. En los que estuvo la Santa Imagen colocada en el Oratorio secreto de estos Príncipes, discurrían con afecto verdaderamente piadoso el modo de desagraviar pública y solemnemente la injuria hecha por los Ingleses Hereges á María; y esta gran Reyna, que quería, que el desagravio fuesse por medio de Ingleses", (J. VILLAFAÑE, Compendio Histórico..., ob cit, pág. 579).

9. "Reverencian los vecinos de la ciudad de Valladolid esta santa imagen en el colegio que los ingleses católicos que en aquel real seminario se crían e instruyen en virtud y letras (para gran bien espiritual de su nación), vuelvan en cultos y veneraciones a la Madre de Dios en esta su santa imagen, lo que los herejes ingleses la ultrajaron y sacrílegos la hicieron, por cuyo motivo y razón, la fue puesto a esta ultrajada imagen el nombre de nuestra señora de la Vulnerata [...] dispuso la soberana reina que los alumnos y seminaristas ingleses que vivían en el seminario inglés de Valladolid, que habían tenido noticia del desacato, quisiesen hacerse inmediatos instrumentos del desagravio"'", (M. CANESI, Historia de Valladolid, t. III, págs. 431, 433).

10. "La cual padece grande necesidad, y paresce que con la presencia de sus Magestades se repararían muchas cosas en aquellas partes, y también que dicen los médicos que conforme la complexión de SM es más apropósito para su salud que esta, aunque también hay otras causas en contrario; pero si la enfermedad de las secas, que ha andado en este lugar los otros años pasados, volviese, se tiene por cierto se tomará resolución en la mudanza". (N. ALONSO CORTÉS, La Corte de Felipe III en Valladolid. Valladolid, Imprenta Castellana, 1908, pág. 7). 
De hecho los reyes entraron en Valladolid el 19 de julio, víspera de santa Margarita, onomástica de la soberana. Aunque Felipe III había manifestado sus deseos de que se produjese una contención en los gastos, el corregidor Antonio de Ulloa deseaba hacer buena manifestación de ellos, para convencer al monarca de la grandeza de Valladolid"1. Un mes después Felipe III y Margarita de Austria visitaban solemnemente el Colegio de los Ingleses. Estaba muy próxima ya la llegada de la imagen profanada ${ }^{12}$. En la sesión del Ayuntamiento de $1^{0}$ de septiembre anunciaba el jesuita inglés Joseph Creswell (vicesuperior de la Misión de Inglaterra que dirigía el Colegio de San Albano), la llegada a Valladolid de la imagen profanada. Entonces los vallisoletanos no sabían bien si se trataba de una Virgen Ilegada de Cádiz o de la misma Inglaterra ("una ymagen de nuestra señora trayda de Yngalaterra"). Los jesuitas invitaban a los caballeros de la Ciudad a participar en la procesión ${ }^{13}$. Lo cierto es que su llegada a Valladolid tuvo una notable repercusión. Como se aprecia en la Relación de Antonio Ortiz, en su Dedicatoria a Isabel Clara Eugenia, fiestas semejantes a las de Valladolid las realizó en Lisboa el archiduque Alberto, su esposo, mientras permaneció como virrey en Portugal ("porque como he entendido en Lisboa hizo su Alteza otra con el mesmo motiuo y solemnidad" $)^{14}$.

Asimismo, la Relación reconocía que la llegada de esta imagen había incrementado notablemente la atracción de Valladolid hacia el Seminario, habiendo visto aumentado también su devoción desde su llegada a partir de septiembre de 1600. Las reacciones fueron contempladas por algunos próximos a los Colegios de Ingleses como un signo de esperanza: "son los principios de tornar a renacer y reflorecer la Iglesia en Inglaterra" ${ }^{\prime 15}$. Y se convirtió en el reclamo devocional del Colegio, pues su fiesta de recibimiento fue calificada por el

11. AMV, Libro 24을 Actas Municipales, "Recibimiento que se hiço a sus magestades", viernes 21 jullio 1600, ff. 111-112v.

12. N. ALONSO CORTÉS, La Corte de Felipe III en Valladolid, Valladolid, 1908, págs 14-15.

13. AMV, Libro del Regimiento de esta muy noble ciudad de Vallid del año de 1600 siendo escriuano mayor del dicho rregimiento Joan de Salzedo, Sesión 1 septiembre 1600, f. 134v.

14. A. de ORTIZ, Relación de la venida de los Reyes Cathólicos al Collegio Inglés de Valladolid en el mes de agosto. Año 1600. Y la collocación y fiesta hecha en el mesmo Collegio, de vna ymagen de Nuestra Señora maltratada de los hereges, dirigida a la Sereníssima señora Infanta de España doña Isabel Clara Eugenia., Madrid, por Andrés Sánchez, 1600. Dedicatorio, s.p.

15. "Presto passará este largo camino y riguroso inuierno de la persecución de los cathólicos ingleses y vendrá el verano sereno, apazible y florido, passara la noche triste y lóbrega de la heregía y començará a amanecer el día claro y alegre de la religión cathólica en esse Reyno: y ya parece a muchos comiença a salir con la venida de vna imagen de nuestra Señora la Virgen María, que los hereges Ingleses maltrataron en Cádiz, y con impiedad sacrílega acuchillaron; y los Cathólicos Ingleses deste Colegio de San Albano, la traxeron y colocaron en el, con tanta fiesta y solenidad, y con tanta grandeza, illustre y deuoto concurso, que muchos les parece que estos son los principios de tornar a renacer y reflorecer la Iglesia de Inglaterra, que este triunfo y exalación y tan ilustre y deuota desta imagen de la santíssima Virgen María, es la aurora deste día", (A. de ORTIZ, Relación de la venida..., ob cit, Madrid 1600, pp. 59v-60). 
cronista Antonio Ortiz como "la más solene y regozijada fiesta que en materia de religión han tenido los Seminarios Ingleses".

\section{LA ENTRADA TRIUNFAL}

"No vio Valladolid desde que se fundó tan grandioso día, como el de la entrada pública y solemne de esta Sagrada Imagen", describía el rector del Colegio años después ${ }^{16}$. Según Manuel Canesi el rey Felipe tuvo que salir hacia la corte madrileña, pues el tiempo de espera se había alargado demasiado. Narciso Alonso Cortés resalta que la salida inesperada del monarca, el día 1 de septiembre hacia Madrid, alarmó considerablemente a los vallisoletanos que estaban pendientes del traslado de la Corte. Temores que todavía se incrementaron más cuando Felipe III envió días después al cardenal de Toledo para acompañar a su esposa a Madrid. Sin embargo la decisión de los monarcas, o mejor dicho del duque de Lerma, de volver a Valladolid, no se publicó oficialmente hasta enero de $1601^{17}$.

Pero no corramos tanto. El monarca había ordenado que se hiciese la procesión de la Virgen mutilada "con la más autoridad posible" ${ }^{18}$. La reina Margarita de Austria fue la que contempló esta traslación solemne. Era precisamente el día de la Natividad de la Virgen, el 8 de septiembre, fiesta que había sido eliminada del calendario anglicano por Isabel de Inglaterra, para ser sustituido por una fiesta dedicada a su persona ${ }^{19}$. La Ciudad había mandado a buscar a la imagen. Su Ilegada a Valladolid no fue pública sino en el interior de un coche cerrado hasta el seminario de los ingleses. La condesa de Santa Gadea la había vestido con un "rico manto azul de tela de plata con flores de oro y puso sobre su cabeza una corona sembrada de rica pedrería" ${ }^{20}$.

Dispuso la reina que la imagen fuese trasladada momentáneamente al convento del Carmen Calzado, en el Campo Grande. Existía la costumbre que desde aquel lugar entrasen solemnemente el obispo y el presidente de la Chancillería en la ciudad, como símbolo de la toma de posesión de sus poderes. Hacía unas semanas que los reyes había andado este mismo camino ${ }^{21}$. La Virgen fue transportada hasta allí, en la litera de la soberana y en secreto, donde la recibieron los frailes carmelitas en su iglesia convenientemente adornada. La

16. ACSA, Serie II, Miscelánea, lib. 12, "Algunas apuntaciones de motivos que ay para favorecer este Colegio o Seminario Inglés de San Albano sito en esta Ciudad de Valladolid".

17. N. ALONSO CORTÉS, La Corte de Felipe III en Valladolid, Valladolid, 1908, pág. 15.

18. AMV, Libro del Regimiento de esta muy noble ciudad de Vallid del año de 1600 siendo escriuano mayor del dicho rregimiento Joan de Salzedo, Sesión 1 septiembre 1600, f. 134v.

19. "Pedía que en tan célebre día triunfase en Hespaña María en su Santa Imagen ya que en Inglaterra en lugar de un Nacimiento, al Cielo y a la tierra admirable, se sustituía otro por tantos y tan patentes títulos torpe y sacrílego", (J. VILLAFAÑE, Compendio histórico..., ob cit, pág. 580).

20. J. VILLAFAÑE, Compendio Histórico..., ob cit, pág. 581.

21. AMV, Libro 24ํำ de Actas Municipales, 21 julio 1600, f. $111 \mathrm{v}$. 
misma litera real, al descubierto, sirvió de andas de la Virgen Injuriada, en su entrada oficial. Precedían el cortejo la nobleza a caballo y rodeaban a la imagen cuatro padres de la Compañía de Jesús y veinticuatro colegiales ingleses con hachas de cera blanca en sus manos. Y como en tantos otros recibimientos solemnes la Virgen entraba en la ciudad por la Puerta del Campo. Los prebendados de la Catedral no estuvieron de acuerdo en asistir a este punto a recibir a la "imajen de Nuestra Señora que trahía de Cádiz maltratada de los herejes". Los comisionados del Cabildo, Francisco Sobrino y Nicolás de Bolaños, explicaron al obispo los inconvenientes que existían a este efecto, no siendo detaIlados en las Actas de sus reuniones ${ }^{22}$. Era el juego de las preeminencias.

Lo cierto es que las campanas de las iglesias comenzaron a replicar hasta la antigua Colegiata de Valladolid, convertida desde 1596 en nueva Catedral. Y allí sí, a su puerta, salió a recibirla el Cabildo, acompañada de la música de la Iglesia Mayor. La colocaron en unas andas de plata y a los hombros de cuatro prebendados fue introducida en la antigua Catedral, donde permaneció toda la noche del 7 de septiembre, rodeada de colegiales ingleses ${ }^{23}$.

Por la mañana la Iglesia Mayor acogió una función litúrgica a la que asistió el Colegio de Ingleses, aunque por la tarde fue conducida en procesión general a San Albano, acompañada de cofradías y religiones, además de doscientos sacerdotes seculares. Cerraba el cortejo el corregidor de Valladolid ${ }^{24}$. La procesión tenía su sentido desde la concentración de gentes en la calle, "el concurso por plazas y calles apenas daba lugar para que caminase", escribía un siglo y medio después el historiador Canesi.

La reina Margarita de Austria, como era habitual en aquel momento, no participó en el cortejo procesional. Antes los monarcas habían enviado, según confirmaba muchos años después el rector Manuel de Calatayud, las más ricas colgaduras, procedentes de Palacio: "Nunca pareció mayor la iglesia que aquel día pues a vista de la Reyna del cielo cupieron muy a satisfacción en ella las dos mayores Magestades de la tierra, asistidos y acompañados de toda la grandeza de su Palacio y Corte ${ }^{\prime 25}$. La soberana se encontraba dentro del pequeño templo del Seminario ("que con devoción, la vio pasar desde su cortina, que

22. ACV, Libro $2^{o}$ del Secreto, Actas Capitulares 1598-1612, Cabildos ordinarios de $2 . I X .1600$ (f. 65), 4.IX.1600 (f.65), 6.IX.1600 (ff. 65-65v).

23. "Se resoluió con pareçer de el Cabildo a que se recibiese la imajen y se guiase del orden siguiente: Ilegada la Santa Imagen a la Iglesia el Cabildo estará sperando y la recivirá y prebendados la traerán desde la litera al Altar donde a de estar en la Capilla Mayor y todo será el juebes a la tarde [...] Puesta la ymagen en el Altar el Cabildo probeerá de lo necessario hasta que se haya de llebar al Collegio Ánglico que será el viernes en la tarde de Nuestra Señora después de vísperas y en este tiempo acompañará a la Santa Imajen los collegiales ingleses", (ACV, Libro $2^{\circ}$ del Secreto 1598-1612, Cabildo 2 septiembre 1600, f. 65).

24. ACV, Libro $2^{\circ}$ Secreto, Cabildo ordinario 6.IX.1600, f. 65v.

25. ACSA, Memorial de Manuel de Calatayud, SI a la Reina Mariana de Austria, por medio de su Camarera la excelentísima señora Marquesa de Balduera en el mes de março año de 1673, f. 4. 
estaba dentro de la misma iglesia, acompañada de sus damas y señores del palacio"). A la puerta del Colegio se había levantado un altar, ante el cual un colegial inglés, una vez llegada la imagen de la Virgen, realizó una breve oración de recibimiento. Una vez concluida ésta, la imagen fue conducida hasta el altar de aquella primera iglesia del seminario por los capitulares catedralicios y sus colegiales ${ }^{26}$.

Comprobó la soberana con sus propios ojos el estado en que había quedado la Virgen después del asalto de Cádiz. Desde esta jornada se iniciaron nueve días de celebraciones litúrgicas, con la estructura habitual de asistencia de instituciones y de sermones: la Real Chancillería o la Inquisición. La Universidad de Valladolid lo hizo a través de las palabras de su profesor de Teología, Francisco Sobrino, después obispo de esta diócesis. El último día fue el de la coronación de la imagen por el primer obispo de Valladolid, Bartolomé de la Plaza $^{27}$. Fue desde esta plática cuando, el prelado de esta ciudad pronunció el nuevo apelativo devocional de la Virgen, la Vulnerata: "nombre que aunque Latino declaraba a todos lo bárbaro de quien se avía atrevido a tales desacatos y lo piadoso de la misma Señora vulnerada en su Imagen para no castigar a los agressores que se atrevieron a cometer tan horrible sacrilegio" ${ }^{28}$.

\section{LA DEVOCIÓN EN LA CORTE Y EL EMBAJADOR INGLÉS}

La Ilegada de la Corte a Valladolid a principios de 1601 supuso el impulso a una ciudad levítica, plagada de sacralización en sus percepciones y en su urbanismo. Los reyes Felipe y Margarita contribuyeron a ello. Eso sí, con la llegada de la Corte San Albano estuvo sometido a la conveniente vigilancia para evitar que ningún espía inglés se aprovechase de la infraestructura colegial. Un sentimiento que produjo pesar en Robert Persons, y por el cual se planteó la posibilidad de trasladar San Albano a Salamanca. Era ésta una ciudad universitaria donde ya se había establecido en 1592 un Colegio de Irlandeses que seguía el mismo modelo de San Albano de Valladolid. Curiosamente, después de la llegada de la Vulnerata, la Corte se podía convertir en un problema para los "Ingleses".

Los monarcas continuaron implicándose personalmente en la devoción a esta Virgen. Señalaba el cronista con un claro tono apologético, que las primorosas

26. "Entretanto que la santa ymagen se pone en el altar se dice el psalmo que el collegio tiene prebenido y luego en poniendo la imaxen en el altar la Capilla de la Iglesia sirá vn motete en canto de órgano o salue, acabada ésta el preste de la Yglesia dirá la oración de Nuestra Señora", (ACV, Libro 2º del Secreto 1598-1613, Cabildo 2 septiembre 1600, f. 65).

27. AMV, Libro $24^{\circ}$ del Regimiento de esta muy noble ciudad de Vallid del año de 1600 siendo escriuano mayor del dicho rregimiento Joan de Salzedo, Sesión 12 octubre 1600, f. 155.

28. M. CANESI, Historia de Valladolid, t. III, págs 434-435. "Título que se la dio por tener el rostro acuchillado, insolencia que cometieron las sacrílegas manos de los impíos herejes, cuando sitiaron Cádiz". 
manos de Felipe III permitieron empezar a labrar un relicario de "piedra lasuli", recubierta de oro para contener el "corazón" del protomartir inglés San Albano; mientras que la reina Margarita labró con sus propias manos un rico vestido para la imagen de la Virgen. Aquella reliquia la había regalado su padre Felipe II en los últimos días de su vida, según confirmó el padre Joseph Creswell.

Así los vallisoletanos pudieron comprobar con sus ojos que los daños de los "herejes" no eran solamente un imaginario de los sermones, sino una patente realidad. Sin embargo para paliar esta impresión, la imagen era cubierta por un transparente, "y aun con todo esse resguardo no sufre la devoción de los fieles el verlas sin entretenerse $\mathrm{e}^{\prime{ }^{29}}$. Unas heridas en la madera que se convertían en Ilamadas a la belleza: "por más que porfiaron los hereges en afearle su divino rostro -escribía el rector Calatayud a los canónigos de la Catedral hispalense- lo más que pudieron conseguir fue dexarle señalado con siete graves heridas pero no borrarle su hermosura que aun se trasluce más entre las sombras de sus Ila$\operatorname{gas}^{\prime \prime 3}$.

No era ésta la única y tampoco la más importante de las advocaciones marianas de Valladolid, ahora convertida en Corte. La Virgen de San Lorenzo se había convertido en la patrona oficiosa de la ciudad. Hasta ella acudía la Corte cuando de rogativas reales se trataba: la salud del monarca, los delicados partos de la reina, los precarios nacimientos de los infantes. Después se encontraba presente en las grandes necesidades de la ciudad, siendo su imagen muy reproducida en pinturas y grabados. Poseía orígenes legendarios como no podía ser de otra forma, mezclados con la invasión musulmana y redescubierta, tras haber sido ocultada en una cueva del río Pisuerga por un sacerdote que la traía desde la villa toledana de Consuegra, por un pastor y su rebaño en plena "reconquista". Así la Virgen de San Lorenzo, Ilamada así por su ubicación en la parroquia de este santo diácono, se convirtió en el siglo XVII en el eje vertebrador de la vida religiosa de Valladolid.

Dos formas de perduración tuvo entre los vallisoletanos la devoción a la Virgen Vulnerata: primero la más inmediata y no inusual en aquellas mentalidades, los milagros. Después la construcción, a partir de 1671, de su nuevo templo debido a la iniciativa de su rector Manuel de Calatayud: "voló la fama por toda la comarca del general aplauso con que fue recibida en Valladolid". Ello atrajo devociones, las mentalidades sacralizadas fomentaban los milagros y una mayor publicidad para la Vulnerata, pues obrado el prodigio y publicado, aumentaba la devoción de los fieles. Ya Juan de Villafañe y Manuel Canesi describían algunos para 1601, año de la Ilegada a esta ciudad. Unos mandaban

29. ACSA, Serie II, Miscelánea, lib. 12, "Algunas apuntaciones de motivos que ay para favorecer este Colegio o Seminario Inglés de San Albano sito en esta Ciudad de Valladolid".

30. ACSA, Serie II, Miscelánea, lib. 12, "Algunas apuntaciones...", ob cit. 
plasmar el prodigio en un lienzo, colocándolo en la iglesia. Otros ofrecían sus muletas después de haberles sido restituída la salud, como testimonio de la sanación. Para otros el signo de agradecimiento era la presentación de ricos ornamentos para dignificar el culto de la misa, mientras que la forma de difusión que elegían algunos beneficiados era la publicación del "favor" ("fue pregonera del prodigio"). Y unos milagros Ilamaban a otros ("noticioso de los milagros de nuestra Señora de los ingleses [...] que diese unas muletas para que se celebrase una misa en su altar por su salud"). Cobraba mayor valor cuando el santuario se convertía en la última meta de un enfermo que había visitado otros lugares con la esperanza de sanar.

El desencadenante del prodigio en ocasiones era una limosna, una oración, una promesa y otras el mero contacto y aplicación de su manto. Margarita de Austria fue una de las habituales en esta forma de milagro, pues como hemos indicado antes recurrió a las competencias de las Vírgenes de Valladolid para el buen parir de su numerosa descendencia, acontecimientos que en ocasiones se convirtieron en demasiado dificultosos. Y eso que, en el primer año de su matrimonio, Felipe III tuvo que oír toda una serie de rumores acerca de la fertilidad de su unión. Dar un heredero era, naturalmente, un servicio a la Monarquía y a la Religión. Ya lo decía Manuel Canesi. "la reina doña Margarita de Austria se prevenía con novenas y dio a luz felizmente los muchos príncipes que vio España, cuyos descendientes hoy venera el orbe".

Por entonces se encontraba a punto de nacer la infanta Ana de Austria, la futura reina de Francia, en el palacio del Conde Duque de Benavente, pues el duque de Lerma todavía no tenía preparada la morada que le iba a vender a Felipe III en la Plaza de San Pablo. Margarita de Austria intentó contar con las suficientes garantías sagradas en tal difícil hora. Ni siquiera la Virgen de San Lorenzo, especialista en estos acontecimientos, era suficiente para semejante momento. Por eso contaron con el manto de la Vulnerata. La nueva infanta nació, pero la reina tuvo numerosas recaídas, no siempre acompañadas por Felipe III, demasiado apasionado por labores cinegéticas. Al final la acción de gracias se transformó en "misa de parida en San Lorenzo", tal y como lo refleja Miguel de Cervantes en la Gitanilla. Pero inmediatamente el rey volvía a la caza, "con no mucho agrado de su regia consorte" ${ }^{32}$.

Así desde aquellos momentos se convirtió en tradición contar con los supuestos "poderes milagrosos" del báculo de Santo Domingo de Silos o la Santa Cinta de la Catedral de Tolosa. Parece que lo presentía la reina, pues murió de sobreparto, cuando contaba con veintisiete años. ${ }^{33}$ Si la soberana consideraba necesario parir con la intercesión de la Vulnerata, los nobles por

31. J. VILLAFAÑE, Compendio Histórico..., ob. cit., pág. 585.

32. N. ALONSO CORTÉS, La Corte de Felipe III en Valladolid, Valladolid, 1908, pág. 28.

33. D. de GUZMÁN, Vida y Mverte de Doña Margarita de Austria, Reyna de Espanna al Rey D. Phelipe III N. Sr. Madrid, por Luis Sánchez, año 1617. 
mimetismo, probaron el mismo procedimiento. Canesi lo documenta para la condesa de Oriarte ("tuvo entonces en Valladolid un recio parto"), solucionado por el contacto con el manto de la Virgen de los Ingleses.

Milagro viviente junto a la Vulnerata se consideró a Luisa de Carvajal y Mendoza, una mujer perteneciente a privilegiada y noble familia, que a imitación de los sacerdotes que de este Colegio salieron hacia Inglaterra y que en algunos casos eran ejecutados, deseó viajar a este reino a vivir el mismo final. Una intención cuasi imposible para una mujer. Y así, "para cumplir voto tan perfecto cuanto difícil y más al frágil sexo de una mujer", como escribía Juan de Villafañe primero y Manuel Canesi después, Luisa de Carvajal creyó contar con la intercesión de la Vulnerata. Allí en Inglaterra, tras nueve años de convivencia clandestina con los católicos, fue apresada. Si salvó su vida fue gracias a las labores diplomáticas del conde de Gondomar.

Precisamente Luisa de Carvajal no se mostró muy partidaria de aquella política que Felipe III, en realidad el duque de Lerma, habían culminado en su acercamiento con la Inglaterra en la que reinaba Jacobo I Estuardo, mostrando este monarca la misma desobediencia que había manifestado su antecesora Isabel I ante la autoridad del romano pontífice, como máxima autoridad de la Iglesia católica.

Aquel Valladolid que había recibido a la Virgen Vulnerata se convirtió en el escenario de la nueva política internacional de la Monarquía, a través del juramento de las paces con las principales potencias: Francia e Inglaterra. Un año después del ataque a la ciudad de Cádiz, Charles Howard recibió de la reina Isabel el condado de Nottingham como premio. Después se dedicó a labores diplomáticas, por lo que fue comisionado en la firma de las paces entre Inglaterra y España, firmadas en Londres en agosto de 1604, ratificadas y juradas por Felipe III en esta ciudad de Valladolid. El embajador que fue enviado a la Corte de España en 1605 fue precisamente el conde de Nottingham. Howard permaneció en Valladolid entre mayo y junio de 1605. En realidad había pretentendido desembarcar en Santander pero la muerte de su correo le empujó hacia La Coruña. Los ingleses anteriormente convertidos en sinónimo de herejes y asesinos se humanizaban en el buen recibimiento tributado a Charles Howard. En realidad aquellos grandes festejos que le tributaron estaban dirigidos a impresionar al "luterano", a complacerle pero también a exaltar a la Iglesia católica. Pudo así contemplar, en la mañana del Domingo de Pentecostés, una magna procesión del Capítulo General de la Orden de Santo Domingo, para acrecentar su asombro por la tarde, cuando pudo ver la solemnidad pantagruélica de la Corte española en el bautizo del príncipe de Asturias, el futuro Felipe IV, nacido en el Palacio Real vallisoletano y acristianado en el convento de San Pablo: "al cruzar el Rey por delante del balcón, el Almirante le hizo una reverente cortesía, á la que SM correspondió quitándose la gorra". El juramento y ratificación de las citadas Paces se realizó el día del Corpus Christi. 
A pesar de todo la polémica estaba servida entre los críticos de la Pax Hispánica. En esa línea se adscriben las palabras de Luis de Góngora cuando describía la visita: "Parió la Reina: el Luterano vino / Con seiscientos hereges y heregías: / Gastamos un millón en quince días / En darles joyas, hospedaje y vino: / Hicimos un alarde ó desatino / Y unas fiestas que fueron tropelías / Al ánglico Legado y sus espías / Del que juró la paz sobre Calvino: / Bautizamos al niño Dominico / Que nació para serlo en las Españas: / Hicimos un sarao de encantamiento: / Quedamos pobres, fue Lutero rico, / Mandáronse escribir estas hazañas / A Don Quijote, á Sancho y su jumento". Toda una traición para muchos, entre ellos para Luisa de Carvajal, hacia los intereses de la Iglesia.

Además de la publicística tan especial que eran los milagros, como se ha indicado anteriormente, la otra forma de difundir la devoción de la Vulnerata fue la construcción de una capilla suficiente y más digna para albergar la imagen de la Virgen y dar cabida a la demanda devocional que progresivamente había despertado. Unos deseos que se empezó a convertir en realidad durante el rectorado de Manuel de Calatayud, desde abril de 1671 hasta diciembre de 1679. El jesuita intentó, y lo logró, convertir estas ansias devocionales en maravedís, y con ello trazar y diseñar un santuario, que fue abierto al culto en octubre de 1679. Mientras tanto, desde que los seminaristas recibieron a la Virgen Vulnerata, no se olvidaron de pronunciar las oraciones de reparación y las letanías de Nuestra Señora "por las necesidades de Inglaterra". Además ante esta imagen debían pronunciar el Juramento de defender y propagar la fe católica, a través de su regreso a Inglaterra una vez concluida su formación: el auténtico objetivo con el cual habían Ilegado a Valladolid.

\section{PALABRA A PALABRA. LADRILLO A LADRILLO: LA CONSTRUCCIÓN DE UNA IGLESIA PARA LA VIRGEN VULNERATA}

En abril de 1671 Ilegaba Manuel de Calatayud al Colegio de San Albano de Valladolid procedente de Salamanca. Pronto empezó a concebir la idea de construir una nueva iglesia dedicada a la Virgen Vulnerata. ${ }^{34}$ Será este religioso la clave fundamental en el proceso de construcción del templo. En los años que Manuel de Calatayud estuvo en este Colegio de los Ingleses, abundó en sus

34. "Apenas me destinó la obediencia para cuidar desta casa santa quando sin reparos de la humana censura dixe en Salamanca, donde me hallaba; si yo fuese tan dichoso que hiciese iglesia a Nuestra Señora la Vulnerata gran cosa sería. Hablé como naturalmente, o por mejor decir sin saber lo que me decía, movido de Dios, y aun por eso hice poco caso de que se riesen de mí. A este Colegio llegué a 25 de abril de 1671, día del glorioso Evangelista San Marcos. Pasáronse como cosa de seis meses sin perder de vista el fin açia donde parece que me encaminaba el cielo, pero sin atreverme a desplegar los labios", (ACSA, Serie II, 1615-1700, lib. 3, Principios y progresos de la milagrosa fábrica de la Madre de Dios Injuriada, 20 diciembre 1679). 
contactos con los arquitectos, ensambladores, escultores y pintores. Él mismo contaba con una formación arquitectónica y ésta le permitía discutir proyectos y avalar planes, contrarios en ocasiones a lo que los maestros de obras estaban dispuestos a llevar a cabo.

De familia noble, pues era hijo de los condes del Real, nació en Valencia en abril de 1635, ingresando en la Compañía de Jesús con dieciocho años. Concluidos sus estudios, fue ordenado sacerdote, siendo profesor de Filosofía y Teología. Primero fue rector de los colegios de Burgos y Segovia, Ilegando desde Salamanca hasta Valladolid en 1671, en donde desempeñó el gobierno de este Colegio de Ingleses. Desde diciembre de 1691 se retiró a Villagarcía y en este Noviciado ejerció sus ministerios sacerdotales entre el pueblo y los alumnos del Estudio. Su salud se encontraba quebrantada pero era un hombre de sobrada experiencia en el gobierno de una casa de la Compañía, por lo cual fue consultor del rector de Villagarcía, incluso en cuestiones artísticas, pues en aquellos momentos se estaba concluyendo la construcción de la Capilla de los Novicios y su retablo. Así primero fue consultor habitual de la casa, pero el visitador-provincial, en enero de 1701, determinó convertirle en consultor extraordinario "ad graviora (en los asuntos más importantes) y cuando su salud diere lugar". Un nombramiento que será renovado anualmente hasta 1710. Murió el 20 de mayo de 1712.

En San Albano Calatayud empezó a comunicarse con maestros de la construcción con el efecto de que le asesorasen sobre las posibilidades del antiguo templo. Ninguna de las soluciones que le proporcionaron agradaron a Manuel de Calatayud. Fue entonces cuando el jesuita decidió visitar algunas de las iglesias de Valladolid para conocer algunos proyectos e ideas, hasta que alcanzó la decisión definitiva: "dejemos de remiendos y hagamos iglesia nueva a fundamentis". En la Corte madrileña le había impresionado profundamente la iglesia de San Antonio de los Portugueses, cuya planta era ovalada, construida bajo la iniciativa del padre de la Compañía Pedro Sánchez ${ }^{35}$. Esta idea de construir un nuevo templo no fue admitida en un primer momento en San Albano ("a carcajadas me respondieron los de casa que tal me oyeron [...] la proposición no dejaba de carecer de loco a las luces de la razón y discreción humana"). Ante semejante reacción el rector decidió actuar unilateralmente. Se dirigió por carta a aquéllos que eran considerados más devotos de la Virgen.

Entre las primeras damas de la nobleza que respondieron a la iniciativa de Calatayud se encontraba la duquesa de Sesa ("antigua bienhechora de esta casa"), que a través de su administrador aportó doscientos ducados. Una limosna providencial para el rector, importante pero no decisiva. A esta aportación se unieron las de las Bernardas de Alcalá de Henares y San Antonio de los Portugueses en Madrid (en cuyos conventos admiró soluciones arquitectónicas que le agradaron).

35. J.J. MARTÍN GONZÁLEZ, y F.J. DE LA PLAZA SANTIAGO, Monumentos religiosos de la ciudad de Valladolid (conventos y seminarios), Catálogo Monumental de la Provincia de Valladolid, t. XIV, parte segunda, Valladolid 1987, pág. 269. 
Estos gestos decidieron a Calatayud a trazar un primer plano de la futura iglesia ("eche mis lineas aunque toscas e imperfectas"). Estas ideas arquitectónicas se las presentó en Salamanca al hermano Pedro Matos, con el objeto de que las pusiera en marcha: "plugo a la Magestad de Dios me enviase la planta acompañada de todos los demás cortes ajustados al arte, asegurándome que después de bien considerado hallaba que se podía ejecutar dicha planta" ${ }^{\prime 36}$.

Con estos diseños en la mano, Calatayud respondió a la obediencia, presentando los planos al provincial de Castilla, Gerónimo de Córdoba. La burla que algunos jesuitas de Valladolid hicieron, no fue compartida del todo por el provincial, aunque contemplaba las dificultades. Como los rumores habían extendido la noticia de que los Ingleses de San Albano deseaban construir un templo, otros maestros hicieron diferentes propuestas. Entonces solamente se quería construir el cuerpo de la iglesia y no circulaba por la mente de Calatayud la posibilidad de añadir capillas.

Finalmente el proyecto se ajustó a un presupuesto que oscilaba entre los diez mil y los doce mil ducados, considerando el provincial que este ajuste era más moderado. A pesar de todo los recursos continuaban siendo insuficientes, a lo que se unía la oposición de los jesuitas. Esto impedía que el provincial diese luz verde a la nueva iglesia: "¿qué medios tiene Vuesa Reverencia?", preguntaba el superior al padre Calatayud, considerando que el presupuesto mínimo para comenzar con las obras debía ser de dos mil ducados. El rector era de los que consideraba que, "abiertos los cimientos, avían de llover limosnas". Las palabras de Calatayud debieron convencer o con ellas insistió al provincial, pues el padre Gerónimo de Córdoba pidió a este rector que primeramente asegurase el sitio. Necesitaba el colegio comprar una casa propiedad del Cabildo, que a juicio de Calatayud, se encontraba en muy mal estado. La tasación que se hizo, sobrepasaba la realidad. El jesuita no tenía ni para comprar esta propiedad. Pero al final, obtuvo el apoyo del provincial, que le prestó los cuatrocientos ducados para cambiar el titular de la misma ${ }^{37}$.

36. ACSA, Serie II, 1615-1700, lib. 3, Principios y progresos de la milagrosa fábrica de la Madre de Dios Injuriada, 20 diciembre 1679.

37. "Este era de la Iglesia Mayor. Es a saber un corral y una casita desdichada de un carretero que se estaba viniendo por momentos a tierra. Entre haziendo mis carabanas con el Cabildo, y después de inumerables postes, infinitos besamanos y otra caterva de penurias, hize mi petición. Tratóse la materia más despacio de lo que yo quisiera. Huvo tasación de Maestros, pero sin ser esto poderosa, a rematar el precio. Les hizo más fuerza a los Señores Canónigos nuestra necessidad para vendernos la casa. Todo el sitio, a juicio de Maestros a todo valer a duras penas llegaba a ducientos ducados, y Dios es Dios que avíamos de dar quatro cientos. Una petición iba y otra venía, y erre que erre pintaba la necessidad desta casa, las reverendas de mi santa Imagen a ver si por aquí podía ablandar los dictámenes de aquellos Señores, pero oleum et operan perdidi. Quien tal imaginará? Por última resolución se me respondió que si queríamos el sitio era 400 ducados, y si no que le dexásemos. Hiriome en el alma el golpe. Detúveme en responder algunos días. Díxele una noche al Hermano Ramos esto va rematado. Aun para el sitio no tenemos. Es verdad, Padre, me dixo [...] Di quenta al Padre Provincial y le dixe sitio aunque caro y la piedad grande de su Reverencia me dixo tomaba por su quenta el sitio y dándome 400 ducados fui con ellos al señor Arzediano con el escrivan del Cabildo", (ACSA, Serie II, 1615-1700, lib. 3, Principios y progresos de la milagrosa fábrica de la Madre de Dios Injuriada, 20 diciembre 1679). 
Finalmente Calatayud se decidió por el maestro Pedro Vivanco, entre muchos otros. Se abrían cimientos, pero no se contaba con piedra: "fuime a la ciudad a suplicarles me diesen permiso para ir reconociendo las entrañas de la plaza de enfrente. Riéronse de mí, pareciéndoles cosa desesperada poder hallar allí cosa de provecho". Calatayud lo atribuía a milagro pero halló piedra para los cimientos. Faltaban, sin embargo, sillares de piedra para las bases de las pilastras. Con este objeto se dirigió Calatayud al duque de Nájera. Este noble había comenzado a construir una capilla de su propiedad junto a la iglesia de San Martín. Pero este proyecto no se había finalizado: "fui trayendo hasta tres o quatro carros de piedra". La decisión no fue tan bien admitida por el cura de San Martín y por un procurador de la Real Chancillería, Ilamado Bañuelos. Ambos plantearon pleito, "con que nos fulminaron". Ambos dos obligaron a Calatayud a tomar otros caminos, aunque murieron poco tiempo después: "andaba la obra con toda su fuga de obreros y albañiles y levantándose los ocho pilares del cuerpo de la iglesia hasta las empostas. En este estado los dexe cubiertos de texa el invierno, y me partí a Madrid, siendo mi primera obligación, por febrero", de $1672^{38}$.

A pesar de todas las burlas, algunas procedentes de jesuitas, en el libro de limosnas se consignaron ya en 1671 aportaciones del provincial Gerónimo de Córdoba, además de la procedente de los padres de la Congregación provincial celebrada este mismo año, de numerosos religiosos de la Compañía de Jesús y de otros que integraban las comunidades de San Ignacio y San Ambrosio, junto a colegiales que habían sido de San Albano. Destacaron, desde el principio a pesar de las competencias que vamos a comprobar en algunos colegios, las cantidades aportadas por rectores de otras casas de la Compañía. Las clientelas jesuíticas, y no únicamente congregaciones, no podían faltar en esta larga lista. Entre ellas se encontraba la sobrina del celebérrimo padre Luis de La Puente (que había sido visitador de este Colegio a principios del siglo XVII), del señor Francisco de Borja (probablemente descendiente del General), además de la duquesa de Gandía. Cantidades también procedentes, y desde el principio de 1671, del arzobispo de Sevilla, del obispo Juan de Rojas desde Ávila, Pedro Godoy en Sigüenza, además de las dineros proporcionados por el prelado de Valladolid.

Se dirigió Calatayud a Madrid, Villa y Corte, donde permaneció durante siete meses, aunque inicialmente tenía pensado residir solamente dos ("nadie que conoce a Madrid le parecerá mucho. Lo que en la verdad es para admirar que en tan poco tiempo se hiziese algo"). Como señala en su Diario, la vida en la Corte no era fácil. Ni contó con el apoyo patente de los jesuitas de la

38. ACSA, Serie II, 1615-1700, lib. 3, Principios y progresos de la milagrosa fábrica de la Madre de Dios Injuriada, 20 diciembre 1679.

39. ACSA, Serie II, libro 17, Libro de la obra de la Iglesia o del templo de este Colegio Inglés de San Albano de Valladolid que hizo con sus limosnas. 
provincia de Toledo ni del apoyo de los procuradores de la de Castilla en la Corte. En los tres primeros meses, Calatayud no obtuvo resultados patentes: "hasta que caiesen algunos pezes tan gordos que taparon a muchos las bocas, y allí adelante lo que eran risas pararon en admiraciones de los de mi provincia y los de la otra en una santa emulación, por no decir otra cosa" ${ }^{\prime 40}$. Tampoco el rector Calatayud tuvo mucho apoyo desde su familia, entre otras cosas porque su padre, de noble condición y empleo como sus hermanos, no le gustaba ver a su hijo mendigando limosnas.

Se dirigió Calatayud a la reina gobernadora Mariana de Austria por tres veces, "y la última tan claro que casi, casi..., en sentir de mi Padre que estaba presente". Por lo menos se consiguió desde aquí que el rey Carlos, al borde de la mayoría de edad, se dirigiese a todos los Tribunales, Consejos y Villa de Madrid para conseguir limosna en este empeño. "y nadie se pudo negar a tan precissa obligación". Por lo menos algo patente había conseguido, pues "como del dicho al hecho en los Reyes suele aver tan largas distancias" ${ }^{\prime 4}$. Así la villa de Madrid y todos los Consejos de la Monarquía, según este decreto del Rey, también contribuyeron. Finalmente Calatayud, repitiendo palabras y memoriales que antes había enviado a la reina Mariana, solicitaba todo el respaldo a Carlos II.

Entonces comenzó Calatayud a redactar memoriales, nunca mostrando desánimo para obtener estos fondos, ("nunca imaginé verme obligado a ser importuno [...] pidiendo de puerta en puerta limosna, save Dios con tanta repugnancia que esto de pedir limosna aun para Dios y sus santos" ${ }^{\prime 2}$. Efectivamente, el rector Calatayud recalcaba que el verdadero objeto de sus palabras era la construcción de un templo, "fabricado ya de puras limosnas". Una iglesia que no debía ser austera, sino todo lo suntuoso y necesario para competir con las de la Corte madrileña.

Manuel de Calatayud no dudó en dirigirse al rey Carlos II, teniendo en cuenta que el monarca era patrono de este Seminario Real y que sus abuelos Felipe III y Margarita de Austria habían apoyado su consolidación en Valladolid. Calatayud era consciente de la mala situación en que se encontraba la Hacienda Real y no se podía atrever a solicitar que el Patronato Real asumiese la fábrica de todo el templo que pretendía construir. No se olvidó el jesuita de

40. ACSA, Serie II, 1615-1700, lib. 3, Principios y progresos de la milagrosa fábrica de la Madre de Dios Injuriada, 20 diciembre 1679.

41. ACSA, Serie II, 1615-1700, lib. 3, Principios y progresos de la milagrosa fábrica de la Madre de Dios Injuriada, 20 diciembre 1679.

42. Memorial de Manuel de Calatayud, SI a la Reina Mariana de Austria, por medio de su Camarera la excelentísima señora Marquesa de Balduera en el mes de março de 1673, pág. 8, ACSA, leg 117, Copias de Memoriales pertenecientes a la demanda que hizo en los años de 1673 y 79 el Padre Manuel de Calatayud, Rector que fue de San Albano para la construcción del nuevo templo de la Vulnerata y su traslación los quales se dispusieron para presentarles a diferentes señores Reyes, Reynas, Cardenales, Grandes, Obispos y otras personas. Son 42. 
usar su realidad familiar y así se lo recordó a la Reina Gobernadora. Tres de sus hermanos habían sido meninos en Palacio. En la fecha de este memorial uno había llegado a puestos muy altos en la carrera judicial (fiscal incluso del Consejo de Aragón y Auditor de la Rota), otro en la Corte de Roma de cuyos servicios podrían informarle el cardenal-jesuita Everardo Nithard y el primogénito, criado perpetuo de los Reyes, fue además gentilhombre de la Cámara. Sin embargo Manuel de Calatayud, como jesuita, era el que más se había alejado de los ámbitos palatinos y del servicio a los Reyes ("y pues mi professión, no permite me pueda servir para lo temporal de VM, se sirvan para lo eterno") ${ }^{43}$. Sin embargo en los años previos a su entrada en la Compañía, y cualquier mérito era necesario para estos momentos, Manuel de Calatayud también había sido menino.

No será ésta la última vez que Calatayud mezclaba las limosnas de la Vulnerata con los asuntos familiares. Su hermano Antonio de Calatayud, fiscal del Consejo Supremo de Aragón, comprobando la falta de medios que su hermano jesuita tenía para la construcción y traslado de la imagen de la Virgen a un nuevo templo construido solo con limosnas, le cedía "de muy buen gana" la merced de hábito que le había sido concedida por el rey Felipe IV. Ya que Carlos II, por los empeños de la Real Hacienda, no había podido desviar una ayuda importante en la construcción de este templo, debía permitir al padre Calatayud beneficiarse de la cesión que le realizaba su hermano Antonio ${ }^{44}$.

Para legitimar sus peticiones de limosna, prueba la dignidad de su empresa a través de la constatación de un milagro, aunque era de los que pensaba que en los milagros existía mucho de oportunismo, con pretexto de encender la devoción: "Vuesa Magestad save quan poco milagreros somos los jesuitas". "Siga, siga Vuesa Magestad -terminaba escribiendo Calatayud en su Memorial a la Reina- por lo menos en esta causa el buen exemplo de sus antepasados". Apeló igualmente al Nuncio del Papa en Madrid, el cual le aportó diez doblones y desde éste fue entrando en conversación con los distintos embajadores, siendo los de Francia y Portugal, los que realizaron mayores aportaciones, además de los enviados de Génova y Venecia. No demasiados buenos resultados tuvo con los miembros de la aristocracia ("que estos grandes señores a veces no ay entenderlos y menos adjetivarlos"). Sin embargo el rector de San Albano no olvidó en su Libro de Fábrica las excepciones a esta regla ${ }^{45}$.

43. "Solo yo, Señora, me hallo el menos asistido de servicios en la Casa de Vuesa Magestad y aun por eso los he buscado prestados de mi Padre y hermanos, que ha sido tan venturosa mi suerte que se hallase con tantos oy para podermelos prestar, sin que les haga falta considerable. $\mathrm{O}$ si quisiera el cielo disponer de suerte las cosas para aprovecharme de todos los servicios y méritos de mi Padre y hermanos en un negocio de tanta gloria de Dios y de su Santísima Madre Injuriada", (ACSA, Memorial de Manuel de Calatayud, SI a la Reina Mariana de Austria..., ob cit, pág. 12).

44. ACSA, leg 117, Copias de Memoriales pertenecientes..., ob cit. Tercer memorial, Memorial de Antonio de Calatayud, fiscal del Consejo Supremo de Aragón al rey Carlos II.

45. ACSA, Serie II, libro 17. Libro de la obra de la Iglesia..., ob cit. 
Había una serie de elementos comunes que se incluían en todos los memoriales que Manuel de Calatayud dirigió a los notables de la Monarquía o a las instituciones. Comenzaba señalando que esta imagen de la Virgen María ya era muy venerada en Cádiz antes del ataque inglés de 1596 y que desde entonces se convirtió en la imagen más injuriada por los herejes ${ }^{46}$. Recalcaba que el Colegio donde se encontraba era fundación del rey Felipe II y que gozó después de la protección material y real de Felipe III y su esposa Margarita de Austria. Después llegaría el olvido. Era entonces conveniente realizar un recuento de aquellas instituciones y personajes que hasta ahora habían destinado limosnas a la Virgen Vulnerata ${ }^{47}$.

En ocasiones el rector de los Ingleses era más duro y señalaba que si la protección requerida no se conseguía, se iba a producir un escándalo. Si este mecenas fracasado era el monarca, desde este gesto se explicaban los malos tiempos de la Monarquía. Los mártires del Colegio de San Albano también se convirtieron en tarjeta de presentación, tarjeta de santidad, para este Santuario de la Virgen: "contra el [este Seminario de Ingleses] en particular huvo declarada persecución, armándose toda aquella multitud de heregías contra estos pocos católicos" ${ }^{48}$. El camino para llegar hasta aquí no fue corto ni fácil: "me ha obligado a peregrinar por el mundo sin perdonar fatigas, ni rendirme a las frequentes dificultades que se ofrecen" ${ }^{\prime 49}$. Sin embargo el rector de San Albano estaba plenamente persuadido que había sido elegido por Dios directamente para llevar a cabo esta singular colecta para la construcción de la iglesia de la

46. "En causa tan sumamente pía y sagrada como es concurrir a desagrauiar la Madre de Dios tan grauemente herida e injuriada; pues quando más venerada de toda la Ciudad de Cádiz fue ahora ochenta años arrojada de su Real trono en la Yglesia Catedral por los herejes yngleses y paseada por las calles más públicas con mil oprobios y afrentas y y no paxando aquí injurias sacrílegas, quitaronle el niño Jhs y los brazos a cuchilladas y por más que porfiaron en afearle su diuino rostro lo más que pudieron conseguir fue dexarsele señalado con siete graues heridas pero no borrarle su hermosura, que aun se trasluze más entre las sombras de sus Ilagas", (ACSA, Memorial de Manuel de Calatayud, SI al Cabildo de la Santa Iglesia Catedral de Sevilla, leg 117, Copias de Memoriales pertenecientes..., ob cit).

47. "Tengo ya tan adelantada la fábrica deste templo que lleuo más de catorce mil ducados de limosnas que he conseguido de Reyes, de cardenales, de Nuncios de Su Santidad, de Auditores de Rota, de Sres Arzobispos, Obispos, Iglesias Cathedrales, de los mayores señores de España, de Embaxadores y Príncipes, de Ciudades, Chancillerías y Consejos con decretos de Su Magestad y la mayor limosna, de todas las que aora me acaba de hazer esta Illustre Ciudad de Cádiz, queriéndose professar parte principal en los desagrauios desta injuriada imagen por hauer merecido la suerte de gozarla por vecina", (ACSA, leg 117, Copias de Memoriales pertenecientes..., ob cit).

48. "De aquí conocerá Vuesa Magestad que aquel Real Seminario de Ingleses de Valladolid deue ser estimado por el más insigne santuario de toda la Christiandad: assí por la milagrosa imagen de la Madre de Dios injuriada, que le haze sombra, como por la recomendación de tantos illustres martyres, hijos suyos que le esclarecen", (ACSA, Memorial de Manuel de Calatayud, SI a la Reina Mariana de Austria, por medio de su Camarera la excelentísima señora Marquesa de Balduera en el mes de março, año de 1673, págs 5-6).

49. ACSA, Memorial de Manuel de Calatayud al Consulado de Sevilla siendo Procurador Francisco de Contreras y Juan Merino de Heredia. Mayo 8 de 1676, leg 117, Copias de Memoriales pertenecientes..., ob cit. 
Virgen. Un nuevo templo para los seminaristas ingleses no hubiese tenido tanto atractivo ${ }^{50}$.

En septiembre de 1672 volvía Manuel de Calatayud a Valladolid. Durante un año la empresa estuvo detenida. Los recursos eran tan escasos que, como confiesa en su Diario, Calatayud tuvo que salir de puerta en puerta pidiendo limosna. Naturalmente, la Ciudad y sus autoridades municipales y el Acuerdo de la Real Chancillería realizaron las primeras limosnas y ofrecieron otras para el futuro. Sin embargo, Manuel de Calatayud, primero salió por los arrabales de Valladolid, "sin perdonar a pobre ni rico [...] era fuerza llevar en la mano ochavos y maravedises porque muchos no se alargaban más que a maravedí, con que era fuerza volverles otro, y al que daba un quarto volvíamosle en ocha$\mathrm{vo}^{\prime{ }^{\prime 1}}$. Después de estas gentes más sencillas, fue hora de adentrarse entre el Valladolid comercial, sintiendo -como señala en su Diario- gran vergüenza de verse mendigando en medio de la Plaza del Ochavo.

Sin embargo el ánimo de Calatayud no se detenía en construir un cuerpo de iglesia, sino que iba diseñando unas capillas laterales. Lo pudo comprobar cuando visitó la iglesia de las Bernardas, con trazas originales de Sebastián de la Plaza, en Alcalá de Henares ${ }^{52}$. Lo consultó con el hermano Matos, aunque el maestro Pedro Vivanco no estaba de acuerdo con estos añadidos. En su Diario confesaba que empezó con la gente de casa, es decir del Colegio de San Albano, a abrir los cimientos de las nuevas capillas, "sin que en ellos huviese más asistencia de Maestro, ni más dirección que la mía" ${ }^{\prime 53}$. A continuación los pilares y los muros fueron subiendo, "y poco a poco dimos con ellos al cabo y

50. "Quando gusta Dios ostentar el brazo de su poder cuida poco su Magestad de la proporción de los medios con el fin, con que según lo que he podido llegar a concebir de mi propria invtilidad, vivo muy persuadido, que desde que me escojió a mi el Cielo para tan gloriosa empresa, decreto la Magestad de Dios corriese solo por su quenta la restauración del crédito de su Madre Santísima", (ACSA, leg 117, Memorial de Manuel de Calatayud a la Reina Mariana de Austria..., ob cit, págs 9-10).

51. "Persona huvo que con gran piedad me preguntó: Padre, será limosna un maravedí que es todo mi caudal? Díxela: eso ha de decir? Esto es agradabilíssima en los ojos de Dios. Démele acá, que espero me le ha de multiplicar el cielo. No despreciaba a nadie, porque me enseñó la experiencia que no daban menos los pobres, sino a una mano mucho más", (ACSA, Serie II, 1615-1700, lib. 3, Principios y progresos de la milagrosa fábrica de la Madre de Dios Injuriada, 20 diciembre 1679).

52. J.J. MARTíN GONZÁLEZ, y F.J. PLAZA SANTIAGO, Monumentos religiosos..., ob cit, pág. 269.

53. "Aquí es de advertir -señala el padre Calatayud con sus acciones providenciales- una providencia rara del cielo, que quando se huvo de señalar la zanja para el cuerpo, yo, sin el menor asomo de capillas y menos el maestro, temiendo la humedad de las aguas, dixe al maestro no me deje VM estrecho el callejón, el porfiaba que quedaba bastante, yo que no. Al fin, contra dictamen suyo, le aparté de modo que fue lo preciso y necessario para lo que sucedió después en la resolución de las capillas. No parece sino que algún Ángel lo iva así disponiendo, porque por qualquier estremo que exhasemos eramos perdidos. Si nos angustábamos nos havíabamos sin sitio para capillas; si nos ensanchábamos más nos poníamos a pique de no servir la pared antigua, y fue Nuestro Señor servido acertásemos sin pensar con la proporción y el medio", (ACSA, Serie II, 1615-1700, lib. 3, Principios y progresos de la milagrosa fábrica de la Madre de Dios Injuriada, 20 diciembre 1679). 
con las tapias con que aunarles al muro de la iglesia". Los deseos de Calatayud se vieron realizados hasta que el tiempo (en forma de invierno) se echó encima y el dinero desapareció.

Cuando la obra se detuvo, fue necesario volver a la demanda. En donde anteriormente le ocasionaba vergüenza, ahora intentó conseguir el valor para limosnear por la Plaza del Ochavo y la Acera de San Francisco, uno de los días más concurridos de la ciudad (él señalaba que era el "día más célebre"): la Víspera de San Miguel, en mayo. Pero llegó un momento en la ciudad se agotaron las limosnas que podían ser destinadas a este fin ("no ha hecho poco Valladolid que según las muchas demandas que estos años allí ha hauido, aun con mucho menos huuiera quedado yo muy contento").

La antes próspera Medina de Rioseco fue otro de los lugares donde buscó dinero el padre Calatayud. En su camino hacia la Ciudad de los Almirantes, le acompañó el hermano Ramos, pues él deseaba arreglar la provisión de pescado que debía llegar al Colegio de San Albano en el tiempo de Cuaresma ${ }^{54}$. En su Diario apuntaba ya algunas tácticas y estrategias, dignas de una picaresca, aunque fuese sagrada, detrás de la palabra predicada: apuntar a la conciencia, según lo que cada uno pudiese aportar ${ }^{55}$.

54. "Llevamos algún favor superior y todo fue menester para no echarnos de hecho del lugar, viniéndome a dar consejos los Alcaldes y rejidores, y como yo más buscaba dineros porfié en quedarme; que si no era oportunidad el daño sería para pues no estaba en mis manos otro tiempo. Al fin vencí y mal que les plugo no pudieron menos de cerderme una restitución que tenían entre manos de mil y quinientos reales. Esto fue por ciudad. Luego traté de pedir estación. Negaronlo, con que a hurtadillas fui visitando los vecinos, aun poco después vino a ser el secreto a voces. No obstante en fuerza de la dependencia callaron, tragando saliva, y yo petita non obtenida iba haciendo mis mangas. Mi compañero ya no podía después ver gustosa acompañarme y yo enfadado le dixe. Hermano, si solo acompañarme se le haze tan questa a mí tan que fuera el pedir, y consuélese con que a mí me toca la peor parte", (ACSA, Serie II, 1615-1700, lib. 3, Principios y progresos de la milagrosa fábrica de la Madre de Dios Injuriada, 20 diciembre 1679).

55. "Aquí en Rioseco me fue Nuestro Señor enseñado varias trazas para sacar limosnas, casi sin saber yo lo que me hacía. Sucedióme que negándome limosna en una tienda de azeite y vinagre, la di las gracias como si me la huviera concedido. Cayóme muy en gracia el caso, con que del saqué una nueva industria para en adelante: que era ir echandolas precio según la esfera y porte de las personas. Si me parecía que me podía dar quatro quartos, decía después de mi arenguita de Vulnerata concluía mi petitorio diciendo: y más hace Vuesa merçed en dar quatro quartos, que otros mil ducados. Si era de dos quartos, de dos quartos la echava; si de un real, de un real. Llegué con mi compañero a una casa, y saliendo la señora a la escalera, di fin a mi arengamiento diciendo: y más estimará Nuestra Señora de vuesa merçed dos reales que de otros un millón. Fuese adentro al parecer convertida, y vulnerada. Entre tanto mi compañero, riéndose me dixo: con que conciencia va vuesa reverencia a estapobre gente a echarles dos reales? Cómo? Mucho le parece? Pues quien la mete en tener sillas y taburetes tan a la vista? Dos ha de llevar. No menos dicho y hecho. Dos vinieron como en ello se contiene. $Y$ en verdad que me valió algunos reales la traza, y fui corriendo properamente por otras partes", (ACSA, Serie II, 1615-1700, lib. 3, Principios y progresos de la milagrosa fábrica de la Madre de Dios Injuriada, 20 diciembre 1679). 
Ya en Zamora acudió a visitar y cumplimentar al obispo, Juan de Astorga, "que era amigo". El prelado no le quería permitir que fuese pidiendo limosna a pie, de puerta en puerta. Pero menos conveniente era para Manuel de Calatayud acudir a sus destinos, bajándose de un coche. En todos estos lugares, grandes y pequeños, intentó verse apoyado por las Justicias y por los curas. Los primeros le debían proporcionar cabalgadura. Señala en su Diario que la más de las veces eran pollinos que adelantaban muy lentamente sus pasos. Las condiciones de vida eran cada vez peores. Las calenturas (que con este concepto se designaban muchos males) aumentaban y en el ánimo de Calatayud apareció la tentación de abandonar y volverse a Valladolid. Pero la salud comenzó a mejorar a fuerza de comer huevos:

"En un lugarsillo llegué al anochecer y fui a la casa del cura, y no estando en casa le huve de esperar y esperar y más esperar. Vino el buen Señor, y con bien mal gesto, obligado del vigor de la Caridad, no pudo echarme de casa. Hizimos colación sin riesgo de quebrantar el ayuno. Tratamos de recojernos, que según era la cama tuvo poco que prevenir. Por los agujeros de la sabana cabía un carro Manchego. Las mantas ediondas, sin almohada, y todo tan sin concierto que en toda la noche pude pegar los ojos, tiritando de frío. Al amanecer, con un día desesperado, ívamos por las casas temiendo se nos escapasen al campo. Llamaba la Justicia: ola fulano, levantaos y abrid: Señor Alcalde, salía una voz, entre gallos y media noche, por acá a estas horas? Si! Abrid! Abría y los ojos sin poderlos abrir, en camisa. Mirad, les decía el Alcalde y el cura, lo que ofreceis a una Imagen Injuriada y Acuchillada por los herejes, a quien se haze templo de limosna. El pobre hombre asustado no sabía que decirse. Al fin apuró instando y ymportunado por volverse quanto antes a la cama y librarse del frío, ofrecía una emina o media emina de trigo, o cevada, ó qualquier cosa. Asentábamosle en la lista, y marchar a otra casa" ${ }^{\prime 56}$.

A pesar de todos estos trabajos, de estas condiciones, limosnas por otra parte muy poco voluntarias, las calamidades fueron muchas y los frutos pocos. La experiencia le enseñó a abandonar en su ruta los pueblos pequeños, eligiendo las villas y ciudades notables, "grandes de substancia". A mediados de aquella Cuaresma regresó a la ciudad del Pisuerga. La obra de la iglesia prosiguió hasta el siguiente invierno. Calatayud decidió dirigirse hacia Segovia en su tercera peregrinación.

Por entonces era rector de este colegio de los jesuitas el padre Diego de Quirós. Un superior que se mostró claramente molesto por la presencia del rector del Colegio de Ingleses, advirtiéndole que no podía salir pidiendo limosna por Segovia, "y que así lo juzgaban todos los Padres". "Ya se ve con esta píldora que bien me sabría la cena", apuntaba a renglón seguido Calatayud. Lo que en realidad le molestaba al rector de Segovia es el que, con la empresa limosneadora de la Virgen Vulnerata le había salido un competidor a su colegio de jesuitas ${ }^{57}$. Una

56. ACSA, Serie II, 1615-1700, lib. 3, Principios y progresos de la milagrosa fábrica de la Madre de Dios Injuriada, 20 diciembre 1679.

57. "Dixome: Padre, ya ve Vuestra Reverencia que los Guardianes no consienten que otros se les entren en su propia jurisdicción. Díxele: Pues yo, hasta agora, tenía entendido que los superiores de nuestros Colegios eran Rectores y no Guardianes. Al fin el me dixo: nosotros hemos de pedir para las quarenta horas, y somos los primeros que nadie. Acabáramos, dixe yo, tiene VR razón que le sobra, y en esa suposición parece que zesa toda la dificultad. El día que yo no diere paso ni me moviere hasta aver vuesa reverencia, concluido su demanda", (ACSA, Serie II, 1615-1700, lib. 3, Principios y progresos de la milagrosa fábrica de la Madre de Dios Injuriada, 20 diciembre 1679). 
actitud que se vio matizada cuando el rector intuyó una visita rápida del provincial de Castilla.

Después se añadieron las prevenciones del corregidor ("el corregidor era algo panzudo"). Él era el que había de autorizar la demanda y asignarle al padre Calatayud un regidor que le acompañase. Después de muchos días comenzó, formando el pequeño cortejo dos criados, que portaban sendas fuentes de plata, además de sus amos y naturalmente el padre Calatayud. Lo primero que había que hacer era dar a conocer la devoción de la Vulnerata, tan popular en Valladolid, pero tan desconocida en Segovia: "ello en buen romanze, fue mucho aparato y poquíssimo fruto, porque con el ruido se espantaba la caza, y en llegando casi nos daban con la puerta en los ojos y volaban los pájaros" $^{\prime \prime}$.

Rápidamente Calatayud tomó camino de regreso a Valladolid. Entrando en su Colegio de San Albano, comprobó que la obra se encontraba apuntalada ${ }^{58}$. Poco reparos se podían hacer. Era invierno y ya no se cocía ladrillo, elemento indispensable para solucionar los desperfectos. A pesar de las dificultades Calatayud consiguió ladrillo y reunió a una junta de maestros. Una de las mayores polémicas de la obra era la linterna que cerraba el cuerpo central, "la niña de mis ojos" como la defendía Calatayud frente a los ataques de la curia provincial.

Las obras de la iglesia se reiniciaron en 1674, después de un año detenidas, "por falta de medios". Por las continuas modificaciones de nuevo escaseó el dinero y tuvo que pedir prestados hasta siete mil reales. Fue entonces cuando el padre Diego de la Fuente Hurtado, a la sazón provincial de Castilla, propuso al padre Calatayud la demanda de Andalucía, coincidiendo con la Ilegada de los galeones.

La empresa no era fácil. Pronto el rector de San Albano se puso en contacto con el Presidente de la Chancillería granadina, Carlos de Villamayor, para pedirle ayuda con su autoridad. También escribió al provincial de Andalucía. Éste había permanecido en Roma, mientras el hermano del padre Calatayud había sido Auditor de la Rota. Las dificultades se sortearon más fácilmente. La licencia para pedir limosna llegó rápidamente. Se trataba de evitar recelos de

58. "Llegué a Medina del Campo donde hallé al Provincial y al Padre Pedro Gerónimo. Este me dixo: que es esto de la obra? Que puntales son estos? Dixele: nada, Padre, no es más que una avertura que hizo a los principios, y esta se está en su primer ser. Como me halló su Reverencia ageno d elo que avía, no quiso contristarme, y dándose al parecer por satisfecho de mi respuesta trató de dissimular. Más yo que me entre oí puntales, puntales fueron que no los pude echar de la cabeza en toda la noche, que pase de claro en claro, y sin poder sosegar, me levanté antes de amanecer. Traté de decir misa, y después fui a despedirme del Provincial y del Padre Gerónimo y les dixe: yo poco podré descansar con esta pesadilla [...] ya si con licencia de vuesa reverencia me partiré al punto, y juntaré los maestros a ver los reparos que se pueden hazer", (ACSA, Serie II, 1615-1700, lib. 3, Principios y progresos de la milagrosa fábrica de la Madre de Dios Injuriada, 20 diciembre 1679). 
competencias como los que habían sucedido en Segovia. El 4 de diciembre de 1675, siguiente a la festividad de San Francisco Javier, salía para Andalucía el padre Calatayud. Tenía previsto Ilegar a Cádiz en la víspera del nuevo año 1676. Las montañas del Guadarrama fueron la primera gran dificultad ("de él milagrosamente salimos vivos porque aviéndonos anochecido no sabíamos el camino y nos faltaba lo más áspero en andar"). En dificultades tan elevadas, no podía faltar la intervención milagrosa de aquel ángel que le guió por la Sierra ("según lo que nos pasó, moralmente ablando, era imposible no despeñarnos cien mil veces si prosiguieramos solos").

En Madrid solicitó licencia al rey Carlos para pasar limosneando a Andalucía, habiendo escogido en primer lugar la ciudad de Cádiz, "todos me aseguraron vna tan gran limosna que pueda servir de exemplar illustre a toda la Andalucía y al mundo todo". En ocho días consiguieron carruaje y compañía para ponerse en camino hacia la capital gaditana. A las incomodidades del camino se unía la mala comida. El día de Navidad el coche que le transportaba volcó ${ }^{59}$. La preocupación de los viajeros fue el estado en el que había quedado éste, elemento vital para seguir en el camino con cierta seguridad. A pesar de todo Cádiz era divisada por Calatayud el 31 de diciembre de 1675.

La capital gaditana había sido tan injuriada y acuchillada por los "herejes ingleses", como lo había sido esta imagen de la Virgen María. Era necesario justificar la presencia de esta imagen en Valladolid ${ }^{60}$, por una decisión de los reyes Felipe y Margarita. Cádiz había sido privada de esta devoción. Después, tras la marcha de la Corte de Valladolid a Madrid, los fallecimientos de Margarita de Austria en 1611 y de Felipe III en $1621^{61}$, el Colegio no había

59. "Corriendo questa abajo pensiamos perecer todos, pero aunque todos salimos bien descalabrados, no tan malo, pues salimos con vida. El coche quedó hecho añicos. En fin, como mejor pudimos, nos lavamos con vino blanco las heridas, y unos ximiendo y otros Ilorando tratamos de conformarnos con la voluntad de Dios y de curar el coche, porque sin él eramos muertos. El coche quedando por tantas partes quebrado recibió muchas ligaduras, y poco a poco nos fuimos a pie al primer lugar, y no pasamos de allí hasta el otro día. Estaba hecho un hospital, y los más sin saber lo que nos avía sucedido, medio atolondrados, cuidamos más del coche que de nosotros", (ACSA, Serie II, 1615-1700, lib. 3, Principios y progresos de la milagrosa fábrica de la Madre de Dios Injuriada, 20 diciembre 1679).

60. "Pues quando más venerada se hallaba Su Magestad en la Iglesia Cathedral de Cádiz de la piedad christiana fue arrojada de su real trono con furia sacrílega en el suelo y arrastrada por las calles más públicas con mil oprobios e ignominias; y aun así no satisfecha la crueldad de los herejes: sacando las espadas apareció la hermosura de su diuino rostro con siete graves heridas y los brazos con su santíssimo hijo acuchilladas se los quitaron", (ACSA, leg 117, Copias de Memoriales..., ob cit, Memorial de Manuel de Calatayud al Comercio de Granada).

61. "Quien creyera Señora [se refiere a Mariana de Austria] que vnos tan felices príncipes havían de parar en lo que finalmente pararon, trasladándose a la mejor razón de Valladolid a Madrid la Corte y no paró aquí la poca suerte de aquel gran santuario pues a esta tan súbita y repentina mudanza, se sobrevino otro mayor accidente, que fue morir muy en breve sus Magestades Católicas, que tanto le favorecieron con que a tan gran pérdida fue furioso quedarse tan pobre y estrecha habitación asta oy", (ACSA, Memorial de Manuel de Calatayud, SI a la reina Mariana de Austria, por medio de su Camarera la excelentísima señora Marquesa de Balduera en el mes de março. Año 1673, pág. 5). 
recibido ni poseía los medios suficientes para la construcción de una "decente capilla" ${ }^{\prime 62}$. Cuando Calatayud Ilegaba a Cádiz confesaba haber gastado catorce mil ducados, "que no es poco milagro en tiempos tan calamitosos", recaudados desde 1671 .

No fue, el rector de San Albano, demasiado bien recibido por el padre Agustín Vázquez, vicerrector de este colegio ("cara de pocos amigos y no le hizo buen estómago"). Calatayud, a pesar de estas oposiciones iniciales, obtuvo importantes logros en Cádiz. La Ciudad aportó dos mil ducados y el obispo Castrillo visitaba al jesuita de Valladolid. Pronto se empezó a asustar el colegio de Cádiz, como antes había temido por su mercado el de Segovia. Los capitulares de su Catedral concedieron al rector del Seminario dos mil ducados. Confesaban estos capitulares que habían entregado esta limosna por la obligación de agradecer a la Virgen los beneficios recibidos ("de que perpétuamente se reconocerán deudores" $)^{63}$.

"Como no tenían traza de venir los galeones me fui a Sevilla", escribía Manuel de Calatayud en el Libro de Fábrica ${ }^{64}$. Se dirigió hacia el Puerto de Santa María y a partir de aquí comenzó el accidentado viaje hacia Sevilla. Los caminos eran una de las barreras más dificultosas entre los hombres que vivieron en estas centurias. La forma de salvar esta distancia, en esta ocasión, era a lomos de un brillante caballo andaluz ("de aquellos fuertes rocinantes que lleva el país"). Así le pareció al padre Calatayud, quizás exagerando. Esta pareja formada por el rector Calatayud y su mozo, cruzando arroyos, cayéndose en sus revueltas aguas, perdiendo maletas y no pudiéndolas abrir porque la llave se había perdido, recordaba a una pareja literaria, maestra en aventuras en los caminos de Castilla. Nos referimos a aquélla formada por Don Quijote y Sancho ${ }^{65}$.

62. "Por raros accidentes se ha uenido a quedar esta milagrossísima imagen tan desvalida y arrinconada que en ochenta años no ha podido lograr vna decente capilla", (ACSA, leg 117, Copias de Memoriales...; Memorial de Manuel de Calatayud al Comercio de Granada).

63. "Iglesia de Cádiz. Ilustrísimo Señor -escribía el padre Calatayud dirigiéndose al Cabildo gaditano- no abrá imagen en toda Cádiz que mayores vltrajes, injurias y agravios padeciese de los herejes ingleses ahora ochenta años que vna de la Virgen Santíssima que oy se venera en el Real Seminario de Ingleses de Valladolid, fundación del señor rey Phelippe Segundo, adonde de poder absoluto la mandó traer, teniendo allí su Corte el señor rey Phelippe Tercero pata procurar desagraviarla, esmerándose en su culto y veneración: no sintió para violencia entonce esta Santa Iglesia Cathedral de Cádiz, viéndose desposeer de alaja tan de su devoción y de todo el pueblo. Como fue desgraciada esta imagen en hauer sido herida y acuchillada de los herejes, fue poco venturosa en que se mudase la Corte a la mejor razón y poco después muriese su Magestad con quien tan singularmente privaba: pues tras estos accidentes se siguió forzosamente la falta de medios con que se ha quedado todo este tiempo sin una decente capilla"'" (ACSA, leg 117, Copias de Memoriales..., ob cit, Memorial de Manuel de Calatayud, SI a la Iglesia Catedral de Cádiz).

64. ACSA, Serie II, Lib. 17, Libro de fábrica..., p. 74.

65. ACSA, Serie II, 1615-1700, lib. 3, Principios y progresos de la milagrosa fábrica de la Madre de Dios Injuriada, 20 diciembre 1679. 
Una vez aclarados diversos asuntos, con el provincial de Andalucía en concreto, Calatayud pudo volver a Cádiz al tiempo de la llegada de los galeones, de los barcos procedentes de las Indias. Sin embargo no dejemos antes de lado la visita a Sevilla. Frente a unos temores iniciales del padre provincial, la Casa Profesa de la ciudad hispalense prestó todo su apoyo al padre Calatayud. Hasta la Casa de Contratación no necesitó ir Calatayud, puesto que su presidente Gonzalo de Córdoba, se los envió a casa en doblones, "sin costarme más que echar una firma". Obtuvo dineros de los barcos que hasta este puerto del Guadalquivir Ilegaban de las Indias, mientras que la Ciudad de Sevilla no contribuyó en nada. No olvidaba Calatayud las cantidades aportadas por la Iglesia Catedral con sus capitulares, además de la Real Audiencia (1060 reales), además del arzobispo hispalense Ambrosio de Spínola.

En Sevilla permaneció desde febrero hasta el Lunes Santo de 1676 cuando se enteró de la llegada de los galeones ${ }^{66}$. La Virgen Vulnerata se había convertido a lo largo del siglo XVII en "patrona y abogada de galeones y flota". En Cádiz encontró nuevo superior, Teodomiro Barba ("que el otro Vice el día antes que llegue le enterraron para que se burlen con mi Vulnerata"). Quería evitar Calatayud entrar de nuevo en competencia con los intereses de limosna del Colegio de Cádiz. Volvió Manuel de Calatayud a Sevilla, durante la primavera, para rematar algunos negocios, entrando el día de San Fernando de 1676 en Granada, después de un camino, como venía siendo costumbre, "trabajossísimo" ("porque en cinco días creo que no dormí una hora"). A pesar de la cercanía de la montaña, confiesa en su Diario el padre Calatayud, que el calor era muy riguroso, lo que le desanimó para seguir caminando después a Málaga, donde ya había obtenido la licencia del rector de aquel colegio. Lo que allí podía obtener (la experiencia le llevaba a calcular que hasta quinientos ducados) lo conseguiría con cierto esfuerzo a su regreso por Madrid. Las limosnas tomaban muchas formas, entre las que se encontraban demandas en iglesias y la platería del Jueves Santo. Así las limosnas no solamente se materializaban en dinero en metálico, sino también -entre otros muchos ejemplos- en fanegas de trigo, ricas telas o vestidos. Destacaron igualmente las alhajas entregadas y consignadas en las correspondientes memorias ${ }^{67}$.

Regresó por Madrid el 28-29 de julio de 1676. Sus efectos retóricos los puso en marcha delante del señor Presidente (del Consejo de Castilla probablemente). Demostró labor de pasillo, paciencia, constancia ante las puertas cerradas. Todo por salvar dos mil ducados prometidos en Cádiz y que, como se desprende de las palabras de su Diario, dependían de la decisión judicial del Consejo. La sentencia fue finalmente favorable a la Vulnerata: "logré la facultad

66. ACSA, Serie II, 1615-1700, lib. 3, Principios y progresos de la milagrosa fábrica de la Madre de Dios Injuriada, 20 diciembre 1679.

67. ACSA, Serie II, libro 17, "Memorias de las alajas y de las personas que las dieron para la traslación de Nuestra Señora de la Vulnerata", Libro de la obra de la iglesia..., ob cit, págs 90v-92. 
-escribía el Rector en el Libro de Fábrica- que me avían negado y juntamente conseguí el que saliéndose a fuera sus Magestades del Patronato del nuevo templo". Carlos II, su futura esposa o su madre no serían los patronos de la iglesia de la Vulnerata. Los jesuitas de San Albano podrían elegirlo.

Por otra parte los religiosos de la Compañía en Madrid se admiraron de las tácticas Ilevadas a cabo por Manuel de Calatayud ("en el Colegio se hazían cruces, y ya miraban con más respeto al pobre mendigo"). Después de la resolución judicial, despachó Calatayud los papeles y poder a Cádiz, para que Juan de Villaviejo, le enviara en menos de un mes la letra de los dos mil ducados. Sin embargo, mientras permanecía de nuevo en la Villa y Corte, no perdió el tiempo Manuel de Calatayud, pues sacó limosneando hasta siete mil reales ("con que traté de volverme a Valladolid a proseguir mi obra bien prevenido") ${ }^{68}$.

Ya había pedido que el Rey destinase dos mil ducados de renta anuales durante el tiempo en que durase la obra de esta iglesia, en la forma que considerase el Presidente del Consejo de Hacienda más rápido en su cobranza. Y pidiendo Calatayud no tenía fin. Solicitaba al rey Carlos que se reservase un juro de seis mil ducados de renta, situado en los pescados, perteneciente a Mariana de Zúñiga y Guzmán, como tutora y madre que era de Francisca María Teresa de Nis Pacheco y de Felipe de Nis Pacheco, su primer marido. La cobranza de este juro pertenecía a la empresa de la Virgen de la Vulnerata por el tiempo en que durase la obra. También pedía a Carlos II que mandase que los indultos que se hacían de los diferentes delitos por parte de la Cámara de Castilla se aplicasen para proseguir la obra, enviando decreto real a la Cámara para hacerlo efectivo ${ }^{69}$.

Solicitó audiencia ante Fernando Valenzuela para presentarle su empresa de la Virgen Vulnerata y también un negocio accesorio tocante a Vicente de Calatayud, su hermano, Auditor de la Rota Romana: "quedo guardando en el Collegio Imperial de la Compañía de Jesús". Valenzuela comenzó en su papel de hombre fuerte en el poder como confidente de la reina Mariana. Después de un pequeño paréntesis, con la mayoría de edad de Carlos II, volvió a la cumbre de su influencia. Recibió formalmente su nombramiento como primer ministro (el primero como tal), gozando así de una clara supremacía sobre los presidentes de los consejos y sobre el resto de los ministros. Pero a Valenzuela le interesaba más el patronato que la política. Los nobles lo rechazaban. Su poder desapareció de la mano de Juan José de Austria.

68. "Con que en cobrando los dos mil ducados de Cádiz como lo espero de la actividad fina del señor don Juan de Villavicecio a quien remití la facultad del Consejo con poder, montara toda la demanda de Andalucía hasta volverme a San Albano cinco mil ducados muy bien cumplidos para gloria de Dios y de su Madre Santísima", (ACSA, Serie II, Lib. 17, Libro de Fábrica..., ob cit, p. 75).

69. ACSA, leg 117, Reliquia de algunos papeles tocante al negocio de la Madre de Dios Injuriada en la demanda de Madrid para la fábrica de su templo. Año de 1673. 
El negocio que Manuel de Calatayud presentó de su hermano, que naturalmente llevó Memorial separado al del templo de la Virgen de los Ingleses, era que tras doce años de Auditor de la Rota, no había recibido puesto más "descansado" en los Consejos de la Monarquía. Así habían sido recompensados otros auditores más modernos.("ipodrá decir el mundo sino que llega a ser penitencia de algún grave delito en mi hermano tan extraordinaria detención en Roma?). Manuel de Calatayud no solo solicitaba respaldo económico para el templo de San Albano, sino que también pedía el Arzobispado de Valencia para su hermano Vicente ("nos ha parecido a sus hermanos sacar la cara a tan justa pretensión" $)^{70}$. Antes de salir de Madrid, el jesuita compraba un rosario de ágatas con botones y cruz de filigrana de plata para la imagen de la Vulnerata, que le costó al Rector cinco doblones.

El 4 de octubre de 1676, el día de San Francisco, entraba en Valladolid. Como el mismo Libro de Fábrica señala la demanda de Andalucía implicaba hasta su regreso a San Albano los cinco mil ducados (cincuenta y cinco mil reales en total), de los que debía descontar ocho mil reales que tenía pendiente del año pasado, "fuera de los gastos de jornadas, alimentos, despachos y rebajas de conducciones". No obstante, para ahorrarse los gastos del viaje, se montó en el carruaje en compañía de un tal Diego Vaquerizo, que muchos eran los que hasta éste Valladolid de pleiteantes y de hombres de leyes continuaban viniendo ("con que aorro a mi Vulnerata el carruaje"). Como señalaba en su Diario Manuel de Calatayud, al dinerito fresco, vinieron los jesuitas de los colegios de Valladolid, San Ambrosio y San Ignacio, y a éstos realizó préstamos el rector de San Albano. Estas cantidades también permitieron limar diferencias con Pedro Vivanco, que algunas discusiones había mantenido con Calatayud. Se pretendía dar principio a las bóvedas. Con veinte mil reales quedó rematado la albañilería de la iglesia y de las capillas. Se comenzó la bóveda de la capilla mayor y después la principal del cuerpo de la iglesia y no pararon las obras a pesar del invierno, "hasta que se concluyó en toda perfeción".

Una vez que la bóveda se hubiese terminado, había llegado la hora de la decoración ("tratamos de adornarla con pinturas"). Al principio se utilizó el temple y no quedó con ello satisfecho el padre Calatayud, encontrando que las pinturas deslucían notablemente la iglesia ("me resolví borrarlas todas y hazerlas de nuevo al oleo"). Fue el maestro Diego Díez Ferreras el que se subió sobre unos caballos para los andamios, con el fin de enmendar las pinturas ${ }^{71}$. Fueron así, dentro de marcos de yeserías, la Inmaculada, El Salvador, San José con el

70. ACSA, leg 117, Carta de Manuel de Calatayud, SI a Fernando Valenzuela para solicitar audiencia, Madrid 10 agosto 1676. Memorial de Manuel de Calatayud, SI a Fernando Valenzuela para después de la Audiencia, a favor de su hermano Vicente de Calatayud.

71. ACSA, Serie II, 1615-1700, lib. 3, Principios y progresos de la milagrosa fábrica de la Madre de Dios Injuriada, 20 diciembre 1679. "De pintar segunda vez al olio los ocho quadros de la bóveda del cuerpo de la iglesia mil quatrocientos y sesenta y seis reales", (ACSA, Libro de fábrica..., octubre 1677, f. 124). 
Niño Jesús, Santa Ana y la Virgen niña, Santa Isabel y San Juan Bautista niño, San Zacarías, San Juan Evangelista y por último María Magdalena.

En realidad, Diego Díez Ferreras fue el pintor más representativo de Valladolid en la segunda mitad del siglo XVII. Enrique Valdivieso ha atendido a su producción, en su estudio sobre la pintura vallisoletana del siglo XVII. Le retrataba cómo un "artista mediano, de escasos recursos técnicos en sus composiciones", que muestra rigidez en sus posiciones y en los gestos de los personajes. Atendió un número considerable de encargos, algunos de ellos procedentes de la Compañía de Jesús, aunque la demanda había disminuido considerablemente de los años iniciales del siglo ${ }^{72}$. En los años que trabajó para Manuel de Calatayud en San Albano, también firmó uno de los cuadros de la serie de la Vida de San Juan Bautista que encargó la cofradía penitencial de la Pasión ("El anuncio del ángel a Zacarías"). Al mismo tiempo para los jesuitas del Colegio de San Ignacio realizaba la "Apoteosis de San Ignacio", la que Enrique Valdivieso consideró la mejor obra conservada de Díez Ferreras ${ }^{73}$.

También a este maestro se debieron los ocho cuadros que ilustran el cuerpo central de la iglesia y a través de los cuales los fieles podían conocer la historia de la Vulnerata. En el primero se representaba la llegada de la flota inglesa a Cádiz en 1596. Después el desembarco y toma de la ciudad, rezando la población ante la Virgen para pedir su intercesión; la profanación de la imagen a martillazos; el arrastre de la Virgen por las calles de Cádiz; la mutilación de la que ya se estaba convirtiendo en la Vulnerata, a cuyos pies se encontraba la imagen del Niño Jesús que antes tenía en su regazo y los brazos de María; la Virgen portada en un carro triunfal, con vestido añadido, recibida por los reyes Felipe y Margarita y algunos jesuitas; la Virgen recibida en el nuevo templo de San Albano y por último la adoración de la Vulnerata por la Corte, entre la que se encontraba Carlos II, su madre Mariana de Austria, además de otros monarcas y santos, una escena imaginaria que nunca se produjo naturalmente. Todos ellos son pinturas sobre lienzo, de forma apaisada ${ }^{74}$. En julio de 1677 pagaba el rector Calatayud los 1600 reales, "por los ocho quadros de la casa de Nra Sra. en los tímpanos de la bóveda principal". Casi dos años después tres mil doscientos por la realización de estas pinturas, sin contar con los bastidores y lienzos, pagados por el provincial castellano de la Compañía de Jesús, el padre Gerónimo de Córdoba. Seguidamente (en febrero de 1679) otros mil ochocientos por la talla de los ocho marcos, tres mil quinientos por dorarles, y por

72. Enrique Valdivieso hablaba de los primeros trabajos que Diego Díez Ferreras realizaba en 1665 en Medina de Rioseco, los once lienzos que ilustraban la vida del emperador Constantino para el retablo de la iglesia de Santa Cruz de la Ciudad de los Almirantes. Tres años después para la cofradía de San José, situada en la penitencial de las Angustias, dos lienzos sobre la vida del Patriarca, referidos a el Taller de Nazareth y su Muerte.

73. E. VALDIVIESO, La pintura en Valladolid en el siglo XVII, Valladolid, 1971, pp. 168-171

74. J.J. MARTÍN GONZÁLEZ y F.J. PLAZA SANTIAGO, Monumentos religiosos de la ciudad de Valladolid..., ob cit, pág. 273. 
las conchas, clavos y colocación cuatrocientos reales. En total diez mil quinientos reales pagaron los jesuitas y este Colegio entre 1677 y 1679 por la realización de este conjunto pictórico ${ }^{75}$.

En la ornamentación de la iglesia y de sus imágenes eran necesarios ricos vestidos: era menester contribuir para el adorno del nuevo templo, una vez que éste hubiese sido concluido. "De algunos -escribía Calatayud en junio de 1679- me consta que apenas teniendo que comer le han ofrecido a esta milagrosa imagen varias y curiosas alajas para su traslación". Si los sencillos habían contribuido con sus limosnas, que tendrían que hacer aquéllos que tenían el sustento cubierto. Manuel de Calatayud, en esta petición de alhajas, se dirigió de nuevo a Carlos II, en fechas más cercanas a la traslación. Donaciones de esta clase ya se habían realizado en otras circunstancias, pero igualmente favorecedoras, por parte de sus abuelos Felipe III y Margarita de Austria ${ }^{76}$.

El día 17 de marzo de 1677 ajustó el rector Calatayud la obra de albañilería con Pedro Vivanco ${ }^{77}$. En la Capilla Mayor, al principio, el rector pensaba colocar un tabernáculo, un retablo en forma de baldaquino. Incluso ya se habían realizado las trazas para el mismo, tal y como Calatayud había visto en Madrid. Sin embargo esta disposición dificultaba los movimientos por la iglesia, por lo que se optó por la solución del camarín, detrás del retablo mayor ${ }^{78}$. Precisamente en este se colocó la imagen de la Virgen Vulnerata después de su traslación. Presidía una capilla mayor cuadrada, que se cubría con una media naranja decorada con yeserías. De la mano de Diego Díez Ferreras procedían los tres arcángeles (Miguel, Gabriel y Rafael) y el Ángel

75. ACSA, Libro de fábrica..., julio 1677, f. 119v; febrero 1679, f. 127v.

76. "Pero ya que Vuesa Magestad se vea obligado a no poder conceder tan pequeña ayuda -escribía Manuel de Calatayud en su segundo memorial a Carlos II- de costa como aquí se pretende dexase Vuesa Magestad por lo menos lleuar de los gloriosos exemplos de sus antepasados: pues desde el señor Rey Phelipe Segundo, fundador de aquel Real Seminario, hasta Vuesa Magestad todos obsequios a tan milagrosa imagen han dexado tantas memorias a la posteridad de su devoción, quantas alaxas proprias suyas están enriqueciendo aquel santuario", (ACSA, leg 117, "Copias de Memoriales...", ob cit).

77. " Toda la albañilería de la Iglesia, capillas, fachada, texados, espexos de ventanas, abrir puertas y ventanas con sus arcos o cargaderos, techos de sobrecapillas y tránsitos a las tribunas de bovediIlas = todas las bóvedas con sus linternas y las bóvedas de las capillas y en conclusión toda la albañilería perteneciente a toda la fábrica del templo quanta ella es por dentro y fuera, sacando los suelos, de manos en veinte mil reales alsandome la obligación de los ducientos ducados de resto de los trescientos a que me obligue a darle al fin de la obra segú el último ajuste de ahora 3 años que solos le quedaba a deber, y yo assímesmo le perdone segú este último convenio entre los dos hasta quinientos reales que me debía dicho Pedro Bibanco; con que libres el y yo de toda obligación pasada, le hago pago con solos dichos veinte mil reales después de haberme cumplido todo lo dicho y referido en el papel de la obligación como en ella se contiene fábrica en Valladolid a 17 de março de 1677 años, sin que por esto dexe de quedar obligado a darme, firme y segura toda la obra conforme lo rezan las escrituras todas pasadas", (ACSA, Libro de fábrica de la iglesia..., ob cit, marzo 1677, f. 117v).

78. J.J. MARTíN GONZÁLEZ y F.J. PLAZA SANTIAGO, Monumentos religiosos de la ciudad de Valladolid..., ob cit, pág. 269. 
de la Guarda, tan necesarios en las devociones jesuíticas. En julio de 1677 lo pagaba el provincial castellano, Gerónimo de Córdoba, con un importe de 515 reales $^{79}$. Coronaba igualmente esta cubrición una linterna, que permitía la entrada de la luz. Diego Díez Ferreras se encargó de pintar y dorar "Ios dos cielos de las linternas"

Hasta la imagen de la Virgen se accedía a través del citado camarín posterior, una función tan necesaria en el culto barroco. En junio de 1677 se había firmado el contrato para la ejecución de este retablo mayor que albergaría a la Vulnerata desde octubre de 1679. El ensamblador sería Blas Martínez de Obregón, con los escultores Juan Antonio de la Peña y Pedro Salvador. A ambos lados de la Vulnerata, una imagen de la escuela sevillana del siglo XVI, se situaban san Eduardo el Confesor, rey de Inglaterra, así como santo Tomás Beckett, otro mártir de los católicos ingleses, anterior a la Ilegada de Enrique VIII Tudor al trono. En la hornacina alta se situó la talla de san Albano, titular del Colegio y protomártir de los católicos ingleses. Los profesores Martín González y Plaza Santiago las dataron en el primer decenio del siglo XVII y se lo atribuyeron a la gubia de Francisco de Rincón, maestro o introductor en Valladolid de Gregorio Fernández ${ }^{81}$.

La espadaña había que adornarla con bolas y cornisas de piedra. En abril de 1678 había Ilegado a la iglesia la imagen de Nuestra Señora de la Concepción, para ser situada en la fachada principal de la misma. La había pagado por adelantado en noviembre de 1677 con un costo de mil seiscientos reales ${ }^{82}$. Indican los profesores Martín González y Plaza Santiago, que a pesar de ser esta iglesia una de las más notables del barroco de Valladolid, la fachada en rigor continuaba siendo clasicista ${ }^{83}$.

"Solo Dios sabe muy bien los infinitos pasos que me costaron, las muchas desazones y disgustos que tuve". Con estas palabras se refería Calatayud a los trabajos que tuvo que realizar para colocar el retablo, los balcones, las pinturas con la historia de la Vulnerata y los marcos. Para estas labores el rector de San Albano consultó con muchos de los oficiales y maestros que en Valladolid se encontraban establecidos. Calatayud tuvo que escuchar muchas opiniones, no solamente de los técnicos, sino de los que lo eran menos. Y de ellos, "caterva de impertinentes", se quejaba en su

79. ACSA, Serie II, Lib. 17, Libro de Fábrica..., ob. cit., f. 79

80. ACSA, Libro de fábrica..., ob cit, julio 1677, f. 119v. En septiembre de 1677, el rector Calatayud pagaba a Diego Díez Ferreras 520 reales por la pintura de los ángeles de la pechina, ACSA, Libro de fábrica..., ob. cit., f. 123v.

81. J.J. MARTíN GONZÁLEZ y F.J. PLAZA SANTIAGO, Monumentos religiosos de la ciudad de Valladolid..., ob cit, págs 272-273.

82.ACSA, Serie II, libro 17, Libro de la obra de la iglesia..., noviembre 1677, ob. cit., f. 121v.

83. J.J. MARTÍN GONZÁLEZ y F.J. PLAZA SANTIAGO, Monumentos religiosos de la ciudad de Valladolid..., ob cit, pág. 270. 
Diario $^{84}$. En definitiva, según caracterizan los profesores Martín González y Plaza Santiago, el templo contaba con un espacio central, dotado de una octogonalidad alargada. Nunca la iglesia dejó de tener la funcionalidad propia de los jesuitas. Por ejemplo con esas comunicaciones entre capillas, actuando estos muros divisorios como contrafuertes ${ }^{85}$.

Construida la iglesia, empeño personal de Manuel de Calatayud, para la cual tuvo reconocimiento de los propios estudiantes ingleses, el siguiente paso era la adecuada traslación de la Virgen Vulnerata a su nuevo templo. Siete eran los altares que poseía la iglesia y para un primer asesoramiento Calatayud se puso en contacto con su hermana, la madre Teresa de Jesús, religiosa del prestigiado Convento de la Encarnación en Madrid. Precisamente de allí habían llegado algunas limosnas para la construcción de la iglesia. Ella debía informar al rector de San Albano sobre los adornos de estos altares ${ }^{86}$. A este aspecto físico se unía el adorno espiritual del templo. Para ello, Manuel de Calatayud, maestro en los contactos, recurrió a su hermano Vicente, antes que abandonase su empleo como Auditor de la Rota en Roma. No solamente obtuvo de él alguna limosna, sino lo más importante, privilegios e indulgencias para el nuevo templo.

De esta forma le envió cinco breves: jubileo para el día de San Albano y para la Dominica infra octava de la Concepción, jubileo de cuarenta horas y altar de las ánimas y por último jubileo de los siete altares durante doce festividades del año. Igualmente, ante la solicitud de Manuel de Calatayud, su hermano le envió tres mil medallas con las efigies de San Albano y Nuestra Señora de la Vulnerata. Igualmente, otra forma publicitaria del colegio, era la necesidad de contar con adecuadas estampas. Calatayud se enteró de las buenas

84. "Tanpoco me detengo en la caterva de impetinentes, así de los nuestros como de los de fuera que cargarían sobre un Christiano. Llegaba uno: esto no podía estar así; y lo otro: no estaría mejor de este modo? Pues para qué pozo: pues para que balcones: pues pinturas parecían escusados: jesús en la linterna! Pues no sería mejor María? Y en la veleta María! Pues no sería mejor Jesús? Todos regoldando pareceres y a ninguno se le soltaba un doblón. En este punto se podía escribir un libro sin fin. Algunas veces me servían de divirtimiento los disparates que decían. Las más eran fuerte jeringa para quien por cien mil partes andava cercado de cuidados. Y puedo afirmarme a decir una cosa: que como yo huviera sabido lograr todas estas ocasiones mucho cielo me avía de dar Dios; si bien siendo Dios quien siempre le espera de su liberal mano", (ACSA, Serie II, 1615-1700, lib. 3, Principios y progresos de la milagrosa fábrica de la Madre de Dios Injuriada, 20 diciembre 1679).

85. J.J. MARTíN GONZÁLEZ, y F.J. PLAZA SANTIAGO, Monumentos religiosos de la ciudad de Valladolid..., ob cit, pág. 270.

86. "Escriví a la Madre Theresa de Jesús, mi hermana en la Encarnación Real, haziéndola saber como mi iglesia tenía siete altares, y que avía muchos con quien cumplir, más que primero que nadie avía de ser la Encarnación y así pregunté de quantos altares se encargaban para el adorno de flores. La respuesta fue tomar uno la Priora, otro la Marquesa de Aguilar, otro la hermana del Conde Estable, y otro mi hermana: dos años faltaban aun, con que las sobraba tiempo para pescar las sedas y componerlas", (ACSA, Serie II, 1615-1700, lib. 3, Principios y progresos de la milagrosa fábrica de la Madre de Dios Injuriada, 20 diciembre 1679). 
habilidades de un religioso capuchino "en abrir laminas". Vino al colegio y en el camarín dibujó la imagen de la Virgen. Los superiores de su orden, le trasladaron a Madrid cuando estaba comenzando estos trabajos. Finalmente desde Madrid envió un buen número de estampas, "arto buenas". Con todos estos recursos, puestos en marcha con la antelación suficiente, el santuario de la Virgen Vulnerata, se encontraba abastecido de los suficientes recursos como para convertirlo en atractivo para las devociones. También la iglesia había ido reuniendo importantes reliquias. Destacaba, según señalaba Manuel Canesi, un pedazo de la correa de la Virgen María, que llegó aquí de la mano del padre logroñés Gregorio de Mendiola, rector de este colegio entre noviembre de 1664 y abril de 1668. Una parte de esta reliquia fue depositada en el colegio de Palencia, mientras que la otra se mantuvo en San Albano ${ }^{87}$.

Tampoco Calatayud podía descuidar la sacristía. Debía ser algo previo a la realización de la traslación, aunque los recursos, eran escasos ${ }^{88}$. Antes de ésta, era necesario dorar el retablo, pero como siempre faltaba el dinero. Pidió prestados quinientos ducados para dar principio a esta obra. En noviembre de 1678 la condesa de Oropesa, camarera de la Vulnerata, aportaba la abultada cantidad a la fábrica de 5500 reales, sin faltar en aquellas navidades el aguinaldo de cien ducados (1100 reales) del provincial de Castilla.

Para obtener nuevos fondos viajó por última vez a Madrid. Era el 1 de mayo de 1679. Se dirigió en memorial a Carlos II, "y aunque le inste varias veces salíme como me entré". Eran malos días, puesto que en agosto de 1679 se habían celebrado por poderes el enlace matrimonial, del monarca con la princesa francesa María Luisa Orleans, aunque hasta noviembre del mismo año no se encontraron los nuevos esposos. En una España donde no se disponía de los recursos necesarios como para que la nueva reina fuese trasladada en un coche lo suficientemente lujoso (y el duque de Alba lo tuvo que conseguir), tampoco había mucho dinero para limosnas: "los tiempos corrían trabajossísimos y se llevan a ellos los cascabeles del casamiento de nuestro Rey, con que pedir a los Señores dinero era ablarles en algaravia", explicaba el rector de San Albano su fracaso

87. M. CANESI, Historia de Valladolid, t. III, pág. 431.

88. "Faltábanos sacristía, y no era fácil disponer la traslación sin este requisito tan principal. Las fuerzas no eran muchas, si bien no faltaba el ánimo. El remedio fue cerrar los ojos y apechugar. Llamé a Bibanco. Díxele mi resolución. Concertamos, y manos a la obra. Lo primero fue cubrir el corralillo, y como unas obras llaman a las otras todo se fue encadenando y componiendo en gracia de Dios. Fue preciso tener cerrada la iglesia por más de un mes, pero después vino a quedar más defendida, sirviendo la nueva sacrsitía de atrio y dando la entrada por la puerta junta a la portería. Entonces se hizieron nuevas las dos puertas, y la interior se retiró más a dentro, y se hizo un sumidero en el patio, porque no sabíamos donde iban a parar tantas aguas por debajo de la iglesia vieja y podían ocasionar notable daño. Con este se huvo de empedrar de nuevo el patio y el paso, y condenar el pozo ediondo de la sacristía. Por este tiempo poco más o menos se dispuso el jardinico, se hizieron los antipechos y del mediodía las dos puertas y celucías", (ACSA, Serie II, 1615-1700, lib. 3, Principios y progresos de la milagrosa fábrica de la Madre de Dios Injuriada, 20 diciembre 1679). 
parcial en Madrid. Parcial porque lo que no consiguió en efectivo lo hizo en alhajas para la iglesia.

Calatayud era claro en sus palabras a la hora de presionar a sus interlocutores. Escribía a Carlos II, en julio de 1679, que "podrá casi a padecer escándalo el mundo si no ve alguna muestra de consideración en Vuesa Majestad con esta Injuriada Imagen. Y cierto Señor que en tiempos en que tan porfiadamente está castigando el çielo a esta Monarquía, no parecer buen arbitrio para aplacar la ira diuina, cerrarle tan del todo las puertas a la piedad y a la misericordia" ${ }^{\prime \prime 9}$. El castigo se llamaba Luis XIV y la política expansionista de una Francia absolutista y centralizada. Ya se lo había escrito muy claramente en el segundo memorial que le envió: "aquella obligación de zelar el culto y veneración desta Injuriada Imagen no la heredó Vuesa Magestad de sus antepasados". Otras veces, cuando a instituciones se dirigía, después de realizar un largo listado de las limosnas conseguidas hasta el momento, Calatayud añadía: "y a vista de tan continuados exemplares a favor desta sagrada imagen, no querrá $V S^{a}$ negarle a Su Magestad la gloria de proseguir con su estrella" ${ }^{\prime{ }^{90}}$.

Manuel de Calatayud no salió de la Villa y Corte hasta que no consiguió los recursos suficientes para saldar la deuda que tenía contraida ("que esto de ser puntual en la paga, aun a los más amigos, les suele saber muy bien, y quedan bien dispuestos para volver a prestar"). Enviaba dineros a Valladolid, para que los doradores continuasen con el retablo, entre otras cosas porque estos maestros y oficiales -como relataba Calatayud- "no comían perendengues.

Si anteriormente el rector de San Albano, se había dirigido por medio de memorial a la reina madre Mariana de Austria, ahora la visitaba desterrada -como narraba el propio jesuita- en la "Imperial Toledo". Era el 27 de junio. Como sabemos en 1674 el rey Carlos había sido declarado mayor de edad, aunque era su hermanastro Juan José de Austria el que dominase los resortes del

89. ACSA, leg 117, "Carta de Manuel de Calatayud a Carlos II, julio 10 de 1679", en "Copias de Memoriales pertenecientes...", ob cit.

90. "Memorial de Manuel de Calatayud al Comercio de Granada", en ACSA, leg 117, Copias de Memoriales pertenecientes..., ob cit. No será Carlos II y su madre Mariana de Austria los últimos monarcas que recibirán memoriales procedentes del Colegio de San Albano. El Rector de los ingleses se dirigió a Fernando VI. De nuevo recordó la fundación del Seminario de manos de su "abuelo" Felipe II. Comparaba el memorialista, parafraseando al padre Yepes, la fama de Jesucristo y la del Colegio de San Albano. Si la venida del Mesías fue pregonada por la persecución que contra él desató el rey Herodes, los ingleses de Valladolid han sido publicitados por los edictos persecutorios decretados por los anglicanos desde su Inglaterra natal, "sirviéndose nuestro Señor de sus enemigos por pregoneros de lo que quería se publicasse". Recordaba el memorialista que si enemigos tuvo este Seminario, también gozó entre sus benefactores a Reyes, Emperadores, Cardenales, obispos, Iglesias Catedrales, además de otros muchos gremios. Felipe II no se contentó con la fundación de este Colegio, sino que a través de su embajador Antonio Fernández de Córdoba, duque de Sessa, acudió al papa Clemente VIII para que confirmase documentalmente esta fundación de San Albano, "y juntamente declarasse el Real Patronato, baxo del qual se avía erigido y fundado para tanta gloria de Dios" "Memorial que con todo rendimiento presenta el Real Colegio y Seminario Ynglés de San Albano de la Ciudad de Valladolid al Rey nuestro señor don Fernando Vlo que Dios guarde, en ACSA, leg 117, Copias de Memoriales pertenecientes..., ob cit). 
poder. Éste bastardo real había nacido de la relación que mantuvo el rey Felipe IV con la actriz María Calderón, conocida como "la Calderona". Desde 1677, Juan de Austria se había puesto en camino hacia Castilla acompañado de un ejército, la aristocracia aragonesa y otros nobles de Castilla. Cuando entraba en Madrid, Ilamado por el monarca (aunque las invitaciones del rey Carlos eran muy relativas en su voluntad), el primer ministro Valenzuela, fue inmediatamente destituido. Fue este gesto, un "auténtico golpe de Estado", en opinión de John Lynch. El hermano de Carlos II fue aclamado como auténtico "mesías político". Cuando el rector de San Albano transitó por las calles de Madrid para limosnear a favor de la Vulnerata, Juan de Austria estaba perdiendo las bases de su poder. De su desastre y caída le libró su muerte en septiembre de 1679. Se ponía así fin a lo que Lynch Ilamó el experimento del "caudillismo español" ${ }^{91}$.

Sin embargo Mariana de Austria y su hijastro eran incompatibles en la Villa y Corte. Por eso la reina madre se exilió a la cercana ciudad de Toledo. "No sé que buenos aires me dieron de probar por aquellos países fortuna", señala Calatayud para justificar su viaje a la capital primada. En los seis días que allí permaneció, logró de la reina mil ducados y joyas procedentes de la soberana y de sus damas, valoradas en trescientos, destinadas a vestir este templo casi ya concluido y al servicio de la imagen de la Virgen. Gozó además del apoyo del cardenal Luis Fernández de Portocarrero, que había sido nombrado cardenal precisamente por recomendación de la reina Mariana de Austria. De él obtuvo cuarenta ducados. Después Portocarrero fue el artífice de la sucesión borbónica a la muerte del rey Carlos. Junto al arzobispo primado, en Toledo, contó Manuel de Calatayud con el apoyo (también económico) de canónigos como el de Francisco Arando ${ }^{92}$.

Entre los jesuitas de la Casa Profesa, el rector de San Albano fue extendiendo la devoción hacia la Virgen Vulnerata, a través de las conocidas estampas. Por Madrid ya había repartido muchas. Para volverse a Madrid, Manuel de Calatayud se ofreció como capellán a Diego de Silva. Debía ser éste un cortesano

91. "España y especialmente su Corte, por los años de 1676, se miraba envuelta en un abismo de discordias, parciales y facciones ambiciosas sobre su gobierno, prevaleciendo en esto el señor don Juan de Austria que, venciendo las oposiciones, se preparaba su alteza para venir a gobernar con el Rey esta monarquía; pero la Reina madre, asistida de su valor, sufrió tan sensible contratiempo con aquel real ánimo que siempre hizo generosamente, rostro a todas las adversidades de esta angustiada corona; cuyos acontecimientos debemos atribuir a la altísima providencia, que muchas veces mortifica las criaturas con el mismo desengaño en las desgracias sin permitir la más luz en el conocimiento de sus males, que el suficiente para conocer que castiga por razones que debemos venerar con sólo la resignación sin adelantarnos a buscar más origen que el de nuestras culpas; pero todo aquel furioso huracán paró en que el año de 79 murió en Madrid, a 17 de Septiembre, el señor don Juan de Austria, hermano bastardo, del rey Don Carlos II", (M. CANESI, Historia de Valladolid, t. III, págs 570-571).

92. "Solía este cavallero (el Canónigo Arando) acudir a nuestras quietes, y los nuestros una noche me molieron a preguntas, si bien no reconocieron el inconveniente toda la quiete. Se la devo a mi Vulnerata y al buen señor Canónigo. El ánima se le salía en ternuras de devoción; dio la hora y como la semilla cayó en buena tierra insensiblemente iba obrando", (ACSA, Serie II, 1615-1700, lib. 3, Principios y progresos de la milagrosa fábrica de la Madre de Dios Injuriada, 20 diciembre 1679). 
que rondaba el Alcázar de Toledo, aquella corte paralela de la reina exiliada, prometido con una tal Francisca Manrique. Habitual y maestro en las prácticas de los galanteos de palacio, tuvo al padre Manuel de Calatayud y a otros jesuitas que acudieron a despedirle, hasta altas horas de la madrugada por la noche toledana, persiguiendo a algunas damas: "el cavallero era de gustaço y le tuvo sin duda ninguna grado en tener a dos circunspectos jesuitas en el terreno, a la luna de Valencia (que se hazía claríssima), como jueces árbitros de los galanteos de palacio, con todos sus perendenges" ${ }^{\prime 33}$.

Sin embargo viajar con Diego de Silva valía la pena para Manuel de Calatayud. Tardaron siete horas, entre las tres de la mañana en que salieron de la Ciudad Imperial hasta las diez de la mañana en que se encontraba en el Colegio Imperial de Madrid. El coche en que habían viajado era del Rey, con la conveniente parada para refrescarse en Illescas. Gracias a la reina Mariana había dinero fresco para ir rematando. Así fueron los viajes del padre Calatayud por esta Castilla, mendigando limosnas, compitiendo con intereses de diversos colegios de la Compañía: "y riase el mundo de mí, que bien tendrá que reir" ${ }^{\prime 4}$.

93. "Los criados estaban avisados estuviesen a las doce de la noche con el coche prevenido en la Plaza de Zocodovel, y a esa hora, que era la que avía de salir del Palacio o Alcazar de cumplir con las leyes del galanteo, avimos de marchar. Avía bastantíssimo tiempo para cenar despacio en la Casa Professa, como lo hizimos. Tuvimos nuestra quiete, y al salir della despidiéndonos de los Padres y tomando del prepósito la bendición, con nuestro atillo debajo del brazo, nos fuimos a casa de Don Pedro Binilla, Fiscal de la Inquisición, abrasar tiempo hasta más de las once, y con un criado suyo marchamos a Zocodabel, no hallando allí rastro ni memoria. Temimos aver llegado tarde y que se huviesen ido. Para asegurarnos subimos al Alcázar, y nos encontramos con sus criados, que también estaban aguardando. Con que salimos de cuidado. Dieron las doce, y ni por esas. Ya cerca de la una le obligaron al buen Señor a desamparar los corredores. Bajo. Hizo señal a sus criados, y dándonos todos por entendidos fuimos a el. Saludámosle. Saludonos. Padres: Señor, aquí estábamos guardando á Vuesa Excelencia, las espaldas. Ea vamos. Fuimos bajando juntos hasta cosa de veinte pasos. Allí en frente vivían unos señores y señoras conocidos, y en la reja baja trataron conversación. Oyéronse por nuestros pecados azia las posadas altas no se que ruidillo que despertó la curiosidad del galán, y dando sus paseos debajo de las ventanas de quando en quando les venía tos a que se siguieron sus parolas, sin saber de cierto si era el sugeto que se echaba menos resonaron unas vozes sueltas que no todos las entienden Lima camuesa yerro, bronze \& que lo eran de las posadas de las damas. Al fin la lima bien esprimida echo zumo y tan dulce que por mas de dos horas bien largas dama y galán se dieron de las astas, sin temor de Dios, de Reyna, ni de los pobres religiosos jesuitas que arremaditos a la pared y en pie estuvimos al terreno sin averlo pecado, como unos santos alabando a Dios y riéndonos blandamente de tan inmensas boverías. Yo pasmaba y volviéndome a mi Vulnerata la decía. Señora, adonde nos aveis traido! Sin poderlo remediar, debajo de la capa del cielo, el cavallero era de gustaço y le tuvo sin duda ninguna grando en tener a dos circunspectos jesuitas en el terreno, a la luna de Valencia (que se hazía claríssima), como jueces arbitros de los galanteos de palacio, con todos sus perendenges", (ACSA, Serie II, 1615-1700, lib. 3, Principios y progresos de la milagrosa fábrica de la Madre de Dios Injuriada, 20 diciembre 1679).

94. "Estos breves apuntamientos pude hazer de mis largas peregrinaciones y aventuras en orden a esta obra del nuevo templo de Nuestra Señora Vulnerata. Ni pueden ir en concreto ni aun medianamente dijeridas, porque de rebato y casi con las espuelas calzadas para Segobia las escriví. Más para que quedase alguna noticia tan qual de tan ardua provincia y tan felizmente conseguida a expensas de las continuas asistencias del cielo, me ha parecido no omitirlas, aun a costa de la censura agria que merecieren", (ACSA, Serie II, 1615-1700, lib. 3, Principios y progresos de la milagrosa fábrica de la Madre de Dios Injuriada, 20 diciembre 1679). 
Entraban en Valladolid el 26 de julio de 1679. Después de tantas dificultades, después de concluida la iglesia, había llegado la hora de trasladar la imagen de la Virgen Vulnerata.

\section{UNA NUEVA ENTRADA TRIUNFAL}

La fecha elegida para la inauguración fue el 22 de octubre de 1679. Para conseguir que la suntuosidad y la celebridad del traslado fuese mayor, Manuel de Calatayud se preocupó de contactar y contar con la participación del mayor número posible de comunidades e instituciones de la ciudad. Primero con el Real Acuerdo, que no se mostró enteramente dispuesto a su participación. Sin embargo, como señalaban los capitulares por estos días, el Acuerdo actuaba en estas celebraciones con cierta posición de superioridad. Esto es lo que motivó que los canónigos escribiesen al citado J Juan de Austria, para exponerle su malestar sobre la actitud de estos señores.

Mayores negativas pronunció el Colegio Mayor de Santa Cruz. Sin embargo las palabras del rector de San Albano parecían ser de mediano regocijo cuando daba noticia de que un día antes de la traslación de la Vulnerata ardió el aposento rectoral de Santa Cruz con un daño de tres mil ducados ("justos juicios de Dios"). Un sentimiento compensa cuando Calatayud advertía que la comunidad de los ingleses fue la primera que les atendió.

Los dominicos se debieron mostrar dudosos ante la invitación o desviaban la petición ("me trajeron entretenido tres semanas"). Si los mercedarios no acudieron a las celebraciones de San Albano, a pesar de ser vecinos de la comunidad, fue por temor a la reacción que podían desencadenar en los dominicos ("el maestro Regata se escusó con jerigonzas y pataratas"). Los capuchinos, en concreto fray José de Madrid, disuadió lo más posible la petición de sermón que se le hizo ("el abito no haze al monje"). Los franciscanos aplazaron su respuesta hasta comprobar lo que respondía el convento de San Pablo (es decir, los dominicos). Por eso Manuel de Calatayud señalaba que "los franciscanos anduvieron culebrando sin decir si ni no". Fue la opinión de la condesa de Oropesa la que les decantó a favor de los jesuitas de San Albano. También contribuyó la aristócrata a que los agustinos calzados, con el maestro Melgar, se uniesen a los sermones: "qual andaba el demonio entre los claustros de las Religiones metiendo obra".

No menos fáciles tuvo las cosas Manuel de Calatayud para conseguir sermones de los jesuitas de San Ambrosio y San Ignacio. Ni siquiera los maestros del primero, profesores de los seminaristas ingleses, se implicaron en esta

95. ACV, Libro $6^{\circ}$ del Secreto, Cabildo extraordinario, 22.VIII.1679, f. 206v.

96. ACSA, Serie II, 1615-1700, lib. 3, Traslación de la milagrosa imagen de Nuestra Señora la Vulnerata a su nuevo templo. Año de 1679 á 22 de octubre, pág. 47. 
traslación: "nos dejaron penitus en la calle, sin querer hazer altar, ni día alguno la fiesta, ni cosa que ubiese a gastar un maravedí". Una actitud que cambió cuando Manuel de Calatayud, como rector, les invitó a comer ("y se me entraron a minimo usque ad maximum por el refectorio a gastar de ajeno $\left.{ }^{\prime \prime}\right)^{97}$. Los ingleses de San Albano, con los jesuitas que allí vivían, se vieron marginados, no solamente por los regulares en general, sino por la propia Compañía de Jesús.

Y si no tenía bastante Manuel de Calatayud con estas dificultades, con estas "inquietudes de las criaturas de la tierra", el rector de San Albano se encontró con el "pleito del cielo". Es decir, con la lluvia. A pesar de las amenazas en forma de nubarrones salió la Virgen Vulnerata del convento de Santa Ana el día 22 de octubre a las nueve de la mañana, acompañada por la Congregación de San Ignacio (es decir, las clientelas de los jesuitas), por el cura de la parroquia de San Lorenzo (a la cual pertenecía este convento de religiosas cistercienses, con su cruz y clerecía) y finalmente las tres comunidades de padres jesuitas. A ellos se unía la capilla musical de la Catedral, entonando en el mismo convento un villancico.

El Cabildo Catedral se había presentado, por medio de dos canónigos comisionados, dos días antes, el 20 de octubre, para invitar a la Ciudad de Valladolid a asistir a esta nueva procesión de la Vulnerata, casi ochenta años después de la primera. Inmediatamente la Ciudad, como institución corporativa de Valladolid, acordó asistir a ambas funciones con cien reales de distribución en cada una de ellas. Sin embargo el tema que realmente preocupaba a los regidores, según las Actas Municipales, era el matrimonio del rey Carlos II con la princesa francesa María Luisa de Orleans y su posible visita a Valladolid después de su celebración ${ }^{98}$.

Igualmente los capitulares estaban ocupados con este enlace. Ya en marzo de 1679 habían recibido, por vía del presidente de Castilla Juan de la Puente Guevara (que había sido Doctoral de esta Catedral) ${ }^{99}$, una carta en la cual en nombre del rey Carlos II, solicitaba le asistiese a los gastos de su matrimonio "con la cantidad que pudiere por vía de donativo gracioso" ${ }^{100}$. Leyendo estas palabras todavía se nos antojan más milagrosas las limosnas que obtuvo Manuel de Calatayud para su templo. En agosto, el Rey no hablaba de dinero, sino de la celebración de una misa y procesión general, con el fin de que prosperase su "feliz estado en el casamiento". La elegida, como sabemos, era la princesa francesa María Luisa de Orleans, sobrina de Luis XIV. El Cabildo

97. "Este quento es de nunca acabar. Vease mi descargo. Aquí no respondieron, por no tener que responder. Corridas y avergonzadas de que se les huviese descubierto tanta caca. Oxico, gestos y más gestos, melindres y más melindres, y huir aun de Nuestra Señora, sin merecerles en toda su traslación ni un maravedí ni una vela, y es de notar que son más devotas desta Santa Casa", (ACSA, Serie II, 1615-1700, lib. 3, Traslación..., ob cit, pág. 48).

98. AMV, Libro de Actas del Ayuntamiento de Valladolid 1678-1681, 20.X.1679, ff. 369-369v.

99. ACV, Libro 6º del Secreto, Cabildo ordinario 23.X.1679, f. 209.

100. ACV, Libro 6o del Secreto, Cabildo ordinario 2.III.1679, f. 198v. 
rápidamente invitó al obispo, al presidente de la Chancillería y a la Ciudad para el mejor lucimiento, traducido en asistencia de las instituciones, para ambas funciones. Se concertó adecuadamente el juego de preeminencias y competencias a la hora de concurrir las distintas instituciones. Pensemos que el Real Acuerdo era un representante cuasi oficial de la autoridad real y la Ciudad no asumía este desplazamiento. Así se había manifestado como conflicto en las fiestas de canonización del rey Fernando de Castilla en $1671^{101}$.

Días antes de efectuarse la traslación de la Virgen Vulnerata a su nuevo templo, los capitulares pedían, por vía de empréstito a Juan López de Talaya, mil ducados. Se habían enterado de la posibilidad de que Carlos II y su nueva esposa pudiesen entrar en las próximas jornadas en Valladolid. Una visita real que eclipsaría plenamente la procesión de la Virgen de los Ingleses y las intenciones de su rector. Con estos dineros pretendían hacer frente a los gastos de desplazamiento del Cabildo fuera de Valladolid para dar la bienvenida a los monarcas. Además se unían otros que el deán debía efectuar para componer y arreglar la escalera del pórtico principal de la escalera de esta Catedral que se había convertido en una obra constante, adornando además la Iglesia Mayor con cincuenta cornucopias ${ }^{102}$.

Aunque en la mente de los regidores estuviese la boda de Carlos II, la procesión de la Virgen de los Ingleses pudo discurrir por las calles más clásicas sobre unas andas acompañados de los pajes de la condesa de Oropesa, por la Plaza del Ochavo, la Platería hasta que llegaron a la calle de Cantarranas. Allí el rector Calatayud se encontró con un aviso importante del Cabildo Catedral. Advertían los capitulares "alborotados" que mandarían la imagen de la Vulnerata a su casa, por los problemas que se habían manifestado con el cura párroco de San Lorenzo que traían en la procesión. Ni corto, ni perezoso, el Rector de San Albano se encaminó a la "carrera" hasta la Iglesia Catedral, pidiendo razón de este conflicto a los canónigos: "esta tan hecha esta imagen a perecer injurias que solo le faltaba a su Magestad el que vuesa merçedes la enviase a su casa, haziendo este desaire". Finalmente este conflicto, que debía ser de competencias y preeminencias como tantos otros, se resolvió.

La procesión continuó hacia el Colegio de los Ingleses por la tarde, cuando el cielo se encontraba más sereno. El palio fue llevado por el corregidor y los

101. ACV, Libro 6o del Secreto, Cabildo extraordinario, 19.VIII.1679, ff. 206-206v. "Llegando la noticia a Valladolid de los felices tratados con la corona de Francia para el casamiento de la muy alta y serenísima señora D’a . María Luisa de Borbón Orleans con nuestro muy católico monarca D. Carlos II, Rey de las Españas y nuevo Mundo, fue de tanta alegría que sin perder tiempo expresó su júbilo en esta Ciudad en prevenciones y regocijos que acreditaron sus grandes demonstraciones, siendo la principal una rogativa a nuestra señora de San Lorenzo, su patrona, saliendo con el Real Acuerdo en procesión general desde la Iglesia Mayor hasta su santa casa, montados todos a caballo, que fue función de grande lucimiento y edificación, en cuyo sistema gobernaba la presidencia de Castilla el muy ilustre señor D. Juan de la Puente Guevara", (M. CANESI, Historia de Valladolid, t. III, pág. 571).

102. ACV, Libro 6o del Secreto, Cabildo ordinario, 13.X.1679, f. 208v. 
regidores. ${ }^{103}$ La imagen de la Virgen fue portada a hombros por los jesuitas, permaneciendo a su lado el padre Calatayud, el protagonista de este empeño ("con los ojos en el cielo, sin apartarlos y encapotado toda la procesión y aun se atrevía a lloviznar"). Volvía a ser ese Valladolid procesional de siempre, recorrido por los altares, erigidos como auténticas obras efímeras ${ }^{104}$.

La iglesia se cerró muy tarde, pues los fieles no dejaban de entrar en ella, "no acertaba a salir de aquel cielo la gente". El templo se encontraba iluminado por seis arañas que habían sido repartidas por los arcos de las capillas laterales, encendidas las cientos de velas en los altares, tantas que algunos retablos se veían deslumbrados. Una vez que la iglesia fue cerrada, la condesa de Oropesa bajó de su tribuna, desprendió las joyas de la imagen (como camarera que era de la Virgen), y sin las alhajas fue colocada en su nuevo camarín y trono. La Oropesa había sido una de los privilegiados más destacados que habían apoyado a Manuel de Calatayud en este su empeño personal, convertido en realidad: "que aun no fue lo más el vestido con ser tanto y digníssimo de una Reyna de España". Nada se quedaba en el tintero del rector Calatayud ${ }^{105}$.

Lo lluvioso de aquel día, hizo que todos los fieles, numerosos por otra parte, que entraron en el nuevo templo, ensuciasen el lugar. Por eso fue necesario que los jesuitas de San Albano y los colegiales ingleses se ocupasen de regarla, barrerla y componerla. Por fin Manuel de Calatayud había logrado construir esta iglesia dedicada a la Vulnerata. Concluyó la jornada con una suelta de campanas. Primero la Iglesia Catedral, después las torres de las parroquias y las espadañas de colegios y conventos. Por fin la suelta del reloj, "que sino es en las mayores o máximas festividades no acostumbra hazer la Cathedral" ${ }^{\prime 106}$.

Como vemos aquellas resistencias iniciales que tanto agobiaron a Manuel de Calatayud, se convirtieron después en adhesiones. Al día siguiente de la traslación, el día 23 de octubre, el Real Acuerdo se sumó a la fiesta, con asistencia a misa y sermón, con el Presidente al frente y los frailes de San Francisco, pasando después al refectorio con la comunidad de jesuitas y seminaristas. Por la tarde la fiesta continuó en la Catedral, con la melodiosa música del arpa. Este mismo día los capitulares recibieron la confirmación del presidente de Castilla de la visita del rey a la que había sido su Catedral. En carta leída un día

103. "Llebó la ziudad las varas del palio que seguía a la Ymagen, concurriendo ansí mesmo todos los caballeros rexidores a la maior solemnidad desta funzión", (ACV, Libro 6o del Secreto, nota añadida 22. X.1679 al Cabildo ordinario 20.X.1679, f. 209).

104. ACV, Libro $6^{\circ}$ del Cabildo, Nota añadida el 22.X.1679 al Cabildo ordinario de 20.X.1679, f. 209.

105. ACSA, Serie II, 1615-1700, lib. 3, Traslación..., ob cit, pág. 50.

106. "Este día que el cielo casi de milagro dejó de llover, llovía sobre mis parabienes, y yo confieso que ya desde entonces me empeçé a olvidar destos mis afanes y cuidados pasados, con el gozo presente que fueron tantos y tan gigantes que solo Dios con su brazo poderoso me pudo dar fuerzas y valor para no averme rendido dellos cien mil veces", (ACSA, Serie II, 1615-1700, lib. 3, Traslación..., ob cit, pág. 51). 
después de que la Vulnerata ocupase su trono en su nuevo templo, el rey Carlos anunciaba su deseo de "apearse" en esta Iglesia Mayor, conforme al ceremonial ejecutado por sus abuelos Felipe III y Margarita de Austria, que por cierto, habían sido mucho mejores patrones de San Albano que él. Se encomiaba al maestro de fábrica a adornar convenientemente la Catedral, y especialmente, el arco de su puerta principal ${ }^{107}$.

El martes 24 continuaron las celebraciones en San Albano sufragado por la mano de la condesa de Oropesa, camarera de la Virgen Vulnerata. En el refectorio se sentaron incluso sus criados, acompañados por los frailes del convento de San Agustín. El día 25 la fiesta fue pagada por la marquesa de Viana, "de igual grandeza" que su compañera en la aristocracia. El refectorio fue cubierto, también por sus criados, además de por su sobrino Juan de Pimentel y por los jesuitas de San Ignacio y San Ambrosio, hacia los que Manuel de Calatayud guardaba alguna advertencia. A estos últimos les acompañaban los hermanos estudiantes. El jueves 26 continuaba la fiesta, de la mano de la Ciudad de Valladolid. La misa y el sermón corrieron a cargo de los clérigos menores ${ }^{108}$.

Las luminarias y castillo de fuegos se vislumbraron el miércoles 25 de octubre, en medio de una noche, que para nada fue lluviosa y sí primaveral (así se atrevió a calificarla Manuel de Calatayud en su Diario). La Plaza del Colegio se Ilenó de gentes, ansiosas de asombro. Desde San Albano contemplaron los fuegos los jesuitas de los otros colegios, "así por los fuegos que fueron razonables, como por el agasajillo del refectorio, siguiendo al refresco un volatin prodigioso que nos tuvo por estremo entretenidos". El Libro de Fábrica de la iglesia especificaba más deliciosamente este agasajillo: un recreo culinario a base de porras y bizcochos de belén, "hechos con cuidado".

La fachada del Colegio estaba adornado por luminarias, variedad de ellas, con "Marías, Jesuses, Josephes y Santiss"”․ Después que el espectáculo hubiese terminado, el cielo, que parecía haberse aliado finalmente con el rector de San Albano, volvió a descargar aguas abundantes, "con arta admiración de todo el lugar por ver la especial providencia de Dios Nuestro Señor en esta traslación de su Madre Santíssima". Desde la providencia y decisión de la divinidad, explicaba Calatayud todo lo resuelto.

A lo largo de todos estos días de fiesta, las gentes no pararon de afluir a la nueva iglesia que contaba Valladolid. Unos Ilevados por la curiosidad, otros muchos empujados por la tradición milagrera de la imagen, que encontraba en sus heridas su singularidad. Las muchas lluvias hicieron del nuevo suelo, algo "intolerable", en expresión del rector. Una concurrencia que continuó

107. ACV, Libro 6º del Secreto, Cabildo ordinario 23.X.1679, f. 209. "Que le participó la resolución de pasar el Rey a los confines de Francia a recibir la reina su esposa y que de vuelta quería honrar con su real presencia a Valladolid, imitando a sus abuelos, haciendo en público la entrada", (M. CANESI, Historia de Valladolid, t. III, págs 571-572).

108. ACSA, Serie II, 1615-1700, lib. 3, Traslación..., ob cit, págs 51-52. 
habitualmente, así la conoció Manuel de Calatayud, y así lo dejó constatado en su Diario. Muchos eran religiosos, cuando las órdenes habían desviado su atención a la iniciativa de este inquieto jesuita. Otros eran canónigos de aquéllos que detuvieron la procesión de traslación en la calle de Cantarranas por un problema de competencias. Tampoco dejaba de asistir el clero secular y todos ellos hacia el altar de la Vulnerata, que debió tener por aquellos tiempos una gran actividad litúrgica. No cubrían estas demandas los tres padres jesuitas que habitualmente residían en la casa: Calatayud como rector, el ministro y el lector ${ }^{109}$.

Sin embargo la nueva pareja real no llegaba y la Catedral de Valladolid se limitaba a colocar seis hachas en su puerta principal, en las noches que la ciudad encendía luminarias para dar así principio a las "fiestas reales del cassamiento de los señores reies" ${ }^{\prime 110}$. La Ciudad se preparó todavía más, pues vieron que esta visita era un recuerdo, una rememoración de aquella ciudad de Felipe II y Felipe III, "el mayor triunfo que podía desear Valladolid". Así dispusieron que las calles por donde hubiese de entrar Carlos II y su nueva esposa fuesen de nuevo empedradas, las paredes de sus casas fuesen pintadas, adornada su Plaza Mayor, su Consistorio y alrededores. Los gremios, que entonces eran cincuenta y uno, renovaron la Puerta del Campo, pintando unos retratos de los reyes a caballo, colocando en una hornacina del mismo la imagen de San Miguel, "príncipe y caudillo de los ejércitos de Dios, protector de las armas de España, amparo y compatrono con nuestra señora de San Lorenzo en esta ciudad". En el Ochavo se dispuso otro arco. La calle de la Platería fue profusamente adornada. La ciudad ordenó hacer juego de cañas con los caballeros ${ }^{111}$.

El dinero se gastó y los reyes nunca llegaron: "en este estado llegó la novedad de que la entrada no había de ser en público, porque el Rey deseaba llegar a la corte con brevedad". Consideraba que la climatología se iba convirtiendo en más rigurosa, y que su salud no estaba dispuesta a ser expuesta a la desconvenencia. Dos comisionados, enviados a Burgos donde se encontraba Carlos II, expusieron al monarca su desconsuelo por las variaciones. Valladolid se tuvo que consolar con salir al paso de los reyes a su paso por la villa de Lerma, cuando se disponían a continuar hacia Aranda de Duero ${ }^{112}$.

109. ACSA, Serie II, 1615-1700, lib. 3,, Traslación..., ob cit, pág. 53.

110. ACV, Libro 6o del Secreto, Cabildo ordinario, 6.XII.1679, f. 210v.

111. M. CANESI, Historia de Valladolid, t. III, pág. 572.

112. "Siguiendo la Ciudad la Corte en aquella villa, hizo su cumplimiento asistida de muchas grandes y caballeros, manifestando el Rey con sus cariñosas demostraciones la estimación que hacía de Valladolid, admitiendo la merced que pedía su lealtad y especial afecto; con esto se despidió, empleando ocho días en esta jornada, con más de cien personas de comitiva, en que gastó muchos ducados; habiéndose restituido a su Ayuntamiento a los cuatro días supo que los Reyes se transferían a Madrid con lo cual se resolvió a que se ejecutasen las fiestas por no poderse dilatar para mejor tiempo por causas que ocurrieron y se pregonaron solemnemente, dando principio a ellas con las luminarias, sábado, nueve de diciembre, el domingo dispararon los fuegos artificiales; aunque la estación era húmeda, concurrieron a verlas muchos de los pueblos circunvecinos y aún de partes muy distantes", (M. CANESI, Historia de Valladolid, t. III, pág. 573). 
Los capitulares en enero del nuevo año de 1680 decidieron tomar un censo (un total de diecisiete mil reales) para pagar los maravedís que se gastaron en los preparativos que hicieron para alumbrar la prevista visita real. El Cabildo tenía pensado adelantarse, como era costumbre, hasta Palenzuela para recibirles $^{113}$. Estos gastos, junto con otros que tuvo que hacer inevitablemente, superaron con mucho -por lo menos así lo exponen los capitulares- las posibilidades del Cabildo. Debía ser mucha la "summa nezesidad", pues como señalaban dos comisionados ante la Ciudad, tenía que recurrir hasta la imagen -como era ya habitual- de la Virgen de San Lorenzo, para Ilevarla consigo a la Catedral. Y esto también conllevaba sus gastos. Conociendo estas circunstancias se debe pensar que los esfuerzos de Manuel de Calatayud fueron todavía mayores para atraer por última vez la atención de la Ciudad hacia la Virgen Vulnerata ${ }^{114}$.

113. "Se tome zenso para estos gastos y se consigne para el desempeño de el principal de el y de sus réditos vna de las dos preuendas añadidas que prezissa únicamente se consume en este desempeño enteramente y no en otra cosa" (ACV, Libro 6o del Secreto, Cabildo ordinario, 29.I.1680, f. 213).

114. ACV, Libro 6o del Secreto, Cabildo extraordinario, 3.IV.1680, ff. 214v-215. Cuando diez años después el rey Carlos II enviudó, se pensó rápidamente en un segundo matrimonio que asegurase la sucesión al trono de España. Se optó por la princesa alemana Mariana de Neoburg y de Baviera, hija del duque de Neoburg y conde palatino del Rhin. Ese mismo año se celebró el matrimonio por poderes. Se trasladó el rey Carlos de Madrid a Valladolid, acompañado de numeroso séquito, con el objetivo de recibirla en la antigua Corte de sus mayores. Las velaciones del matrimonio se celebraron en mayo de 1690 en la iglesia del convento de los franciscanos descalzos de San Diego, muy próximo al Palacio Real, viviendo a partir de ahí la ciudad importantes celebraciones. El 11 de mayo abandonaban la nueva pareja real Valladolid, saliendo hacia Madrid por la Puerta del Campo. La ciudad recordó este acontecimiento con una placa que estuvo colocada en el dicho convento de San Diego hasta el derribo de esta parte del edificio en 1895. Casimiro González García-Valladolid así nos lo recuerda, tomando como base el diario manuscrito de Roque de Soria, sobre los sucesos acontecidos en Valladolid entre 1690 y 1730. Canesi también lo había detallado en su Historia. C. GONZÁLEZ GARCíA-VALLADOLID, Valladolid, sus Recuerdos y sus Grandezas, t. I, Valladolid, 1900, págs. 307-308. 